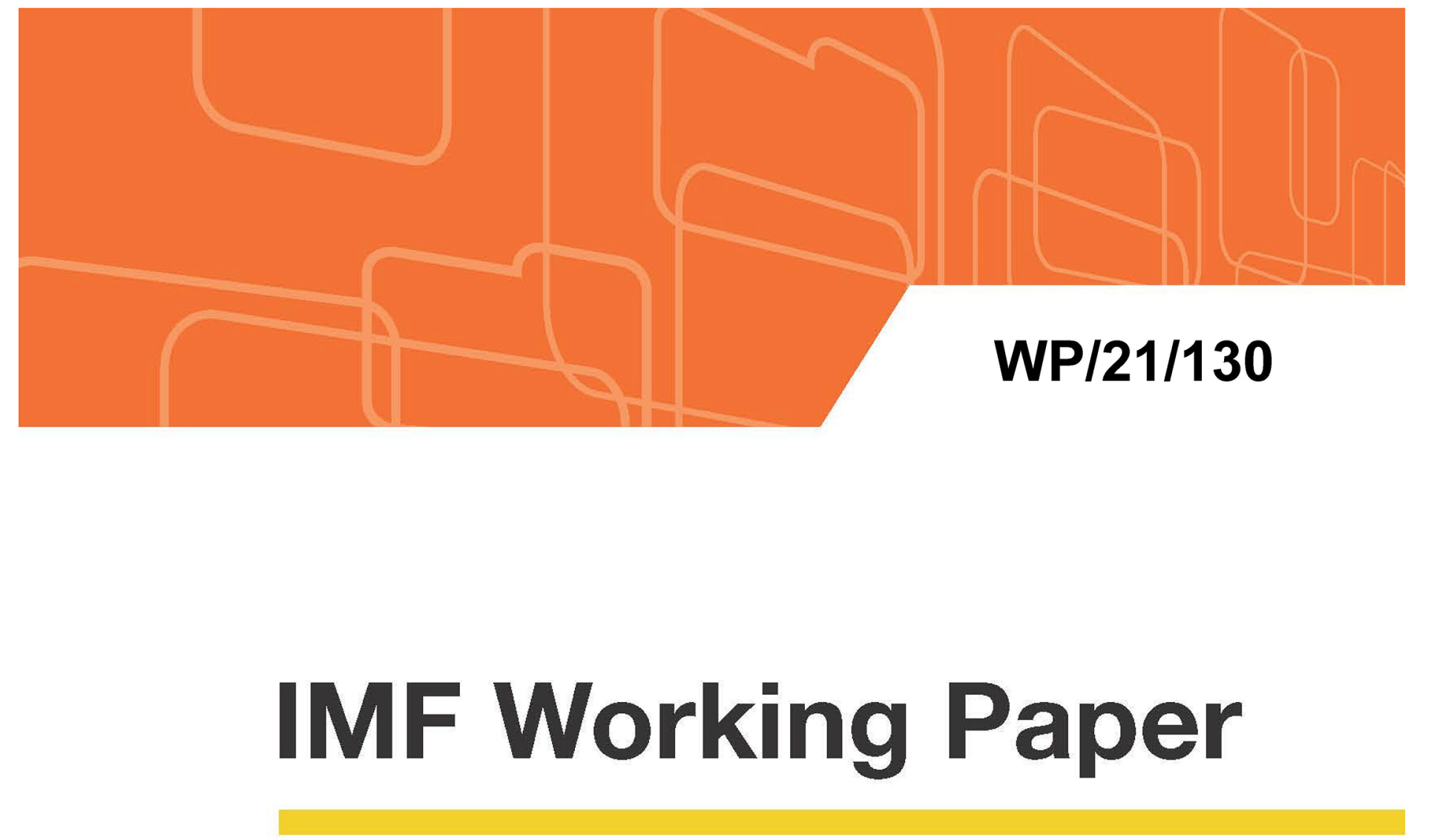

\title{
Who Doesn't Want to be Vaccinated? Determinants of Vaccine Hesitancy During COVID-19
}

by Era Dabla-Norris, Hibah Khan, Frederico Lima, Alexandre Sollaci

IMF Working Papers describe research in progress by the author(s) and are published to elicit comments and to encourage debate. The views expressed in IMF Working Papers are those of the author(s) and do not necessarily represent the views of the IMF, its Executive Board, or IMF management.

$$
\text { I N T E R N A T | O N A L M O N E T A R Y F U N D }
$$




\title{
IMF Working Paper
}

Asia and Pacific Department

\section{Who Doesn't Want to be Vaccinated? Determinants of Vaccine Hesitancy During COVID-19'}

\author{
Prepared by Era Dabla-Norris, Hibah Khan, Frederico Lima, and Alexandre Sollaci \\ Authorized for distribution by Era Dabla-Norris
}

May 2021

\begin{abstract}
IMF Working Papers describe research in progress by the author(s) and are published to elicit comments and to encourage debate. The views expressed in IMF Working Papers are those of the author(s) and do not necessarily represent the views of the IMF, its Executive Board, or IMF management.
\end{abstract}

\begin{abstract}
Quick vaccine rollouts are crucial for a strong economic recovery, but vaccine hesitancy could prolong the pandemic and the need for social distancing and lockdowns. We use individual-level data from nationally representative surveys developed by YouGov and Imperial College London to empirically examine the determinants of vaccine hesitancy across 17 countries and over time. Vaccine demand depends on demographic features such as age and gender, but also on perceptions about the severity of COVID-19 and side effects of the vaccine, vaccine access, compliance with protective behaviors, overall trust in government, and how information is shared with peers. We then introduce vaccine hesitancy into an extended SIR model to assess its impact on pandemic dynamics. We find that hesitancy can increase COVID-19 infections and deaths significantly if it slows down vaccine rollouts, but has a smaller impact if all willing adults can be immunized rapidly.
\end{abstract}

JEL Classification Numbers: I12, I18

Keywords: vaccine hesitancy, COVID-19, SIR model

Author’s E-Mail Address: ABalduinoSollaci@imf.org; EDablaNorris@imf.org; FLima@imf.org; HKhan2@imf.org

\footnotetext{
${ }^{1}$ We would like to thank Sarah Jones at Imperial College London for sharing earlier versions of the data and participants in IMF seminars for their useful comments. The views expressed in IMF Working Papers are those of the author(s) and do not necessarily represent the views of the IMF, its Executive Board, or IMF management.
} 


\section{Table of Contents}

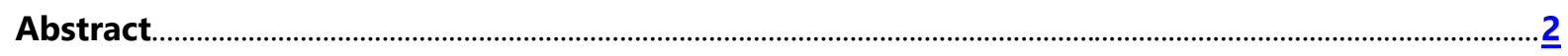

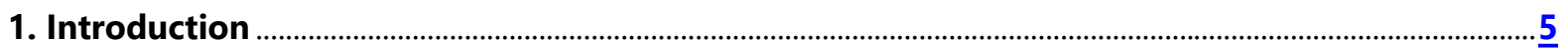

1.2 Relationship to the Literature ………………………..............................................................................

2. Data and stylized facts..................................................................................................................

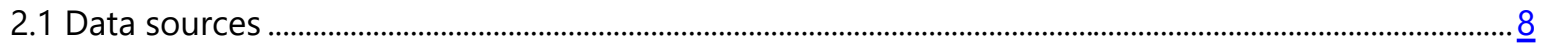

2.2 Vaccine hesitancy across countries and over time .....................................................................................

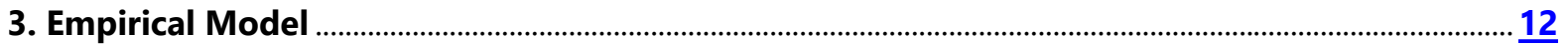

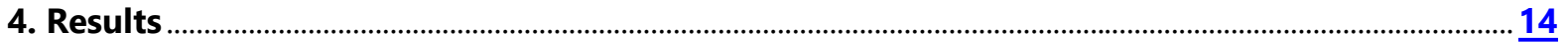

4.1 Demographic characteristics and Vaccine access...................................................................................14

4.2 Beliefs Concerning COVID-19, Vaccines, and Trust in the Government ...............................................15

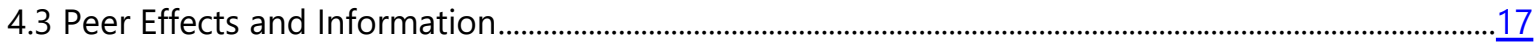

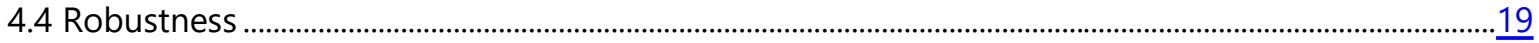

4.5 Policies to Decrease Vaccine Hesitancy ………………………………………………………………......

5. Vaccine Hesitancy and the Pandemic Dynamics........................................................................... 22

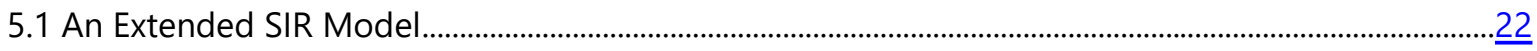

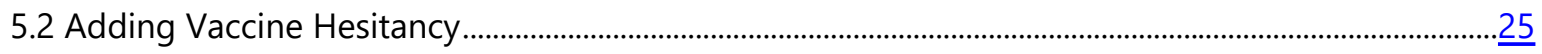

5.3 The Toll of Vaccine Hesitancy ............................................................................................................

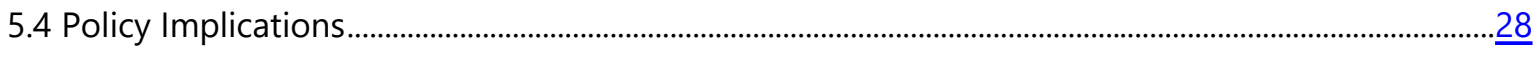

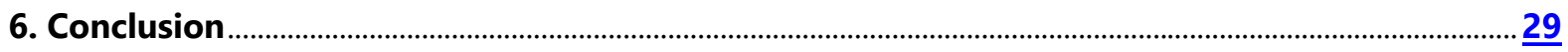

7. References

\section{Appendices}

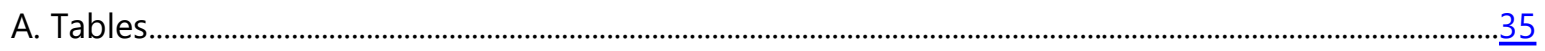

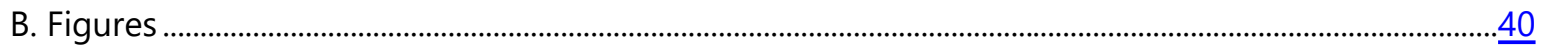

C. Vaccine Hesitancy and the Pandemic Dynamics: COVID-19 Cases ............................................................41

CInternational Monetary Fund. Not for Redistribution 


\section{Tables}

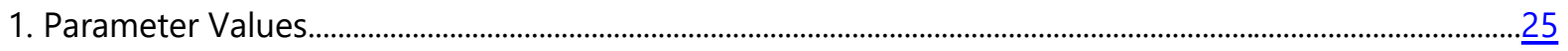

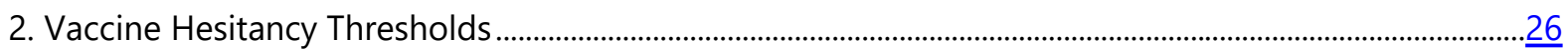

\section{Figures}

1. Variation in vaccine hesitancy across countries ............................................................................................10

2. Variation in vaccine hesitancy within countries: UK and Germany.............................................................11

3. General vaccine acceptance and COVID-19 vaccine intent.............................................................................

4. Trends in COVID-19 vaccine demand over time.............................................................................................12

5. Impact of age, gender, and occupation on the probability of vaccination................................................15

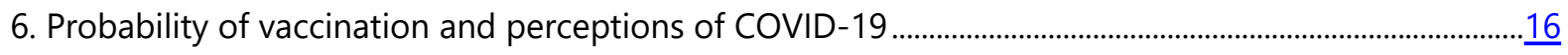

7. Probability of vaccination, side effects and effectiveness .................................................................................17

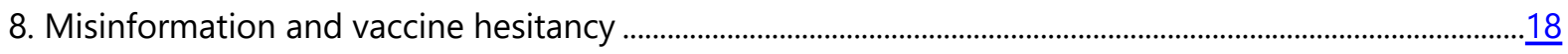

9. Trust in government and vaccine effectiveness .........................................................................................

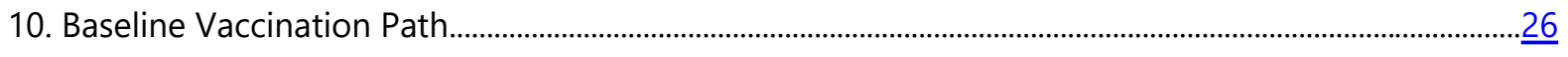

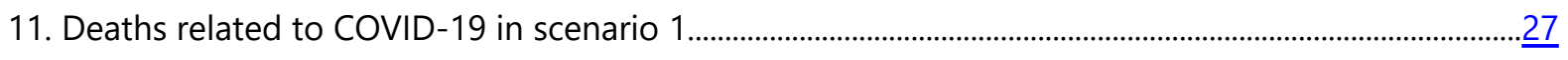

12. Deaths related to COVID-19 in scenario 2 ................................................................................................. 


\section{Introduction}

Our best hope in the fight against COVID-19 and the global economic recovery rests on widespread immunization. So far, vaccine rollouts in many parts of the world have been beset by supply constraints and limited vaccine availability. Yet, even when these issues are resolved, insufficient vaccine demand could still pose a serious challenge. Vaccine hesitancy and refusal could mean that not enough people in a community are immunized above levels required for herd immunity - a threshold that remains an active area of research but that would likely require vaccinating a large majority of the population. Failure to reach herd immunity would halt progress against COVID-19 and place the economic recovery at risk. In this context, it is crucial to understand what drives vaccine hesitancy, and how it could shape pandemic dynamics.

Skepticism towards vaccines, ranging from slight hesitancy to outright refusal, is not unique to COVID-19. Vaccine hesitancy was seen as a growing challenge before the pandemic, even for well-established immunizations with proven track-records of safety and effectiveness like the measles or polio vaccines. ${ }^{2}$ Reasons for low vaccine uptake are typically centered on concerns about their safety, potential side effects and efficacy (Figueiredo et al., 2020), frequently fueled by misinformation or lack of trust in government and health systems (Martinez-Bravo and Stegman, 2021). Vaccination can also be a victim of its own success, as the benefits of widespread vaccination become less salient when disease incidence has been dramatically reduced (Oster, 2018).

To examine the determinants of vaccine hesitancy during COVID-19, we use individual-level data from the COVID-19 Behavior Tracker, a set of nationally representative surveys conducted by YouGov and Imperial College London across 17 countries between November 2020 and April 2021. We start our analysis by documenting stylized facts about COVID-19 vaccine hesitancy across countries and over time. Next, we investigate empirically how vaccine demand varies across demographic groups, risk attitudes, and self-reported trust in government. In the second part of the paper, building on work by Radzikowski and Dizioli (2021), we extend a canonical susceptible-infectious-recovered (SIR) epidemic model to examine the implications of vaccine hesitancy for pandemic dynamics.

Averaging across our entire sample of over 114,000 observations, only about 61 percent of respondents agree or strongly agree that they would take the COVID-19 vaccine if available to them. However, there is significant variation in vaccine hesitancy across and within countries, and over time. This suggests that even if certain countries or regions achieve herd immunity through

\footnotetext{
2 The WHO defines vaccine hesitancy as "the reluctance or refusal to vaccinate despite the availability of vaccines." This trend has accelerated in recent years, in tandem with a general decline in trust in institutions, so much so that the WHO named vaccine hesitancy as one of the top ten threats to global health in 2019, alongside climate change. See https://www.who.int/news-room/feature-stories/ten-threats-to-global-health-in-2019 (Jan 18, 2019).
} 
vaccination, neighboring countries or regions may not, which could prolong the pandemic. Vaccine hesitancy also seems to be declining over time, especially in countries that are further along their vaccination programs.

Next, we focus on systematic differences in vaccine intent across demographic groups. Older people, who have the largest morbidity and mortality risks linked to COVID-19, report a much higher willingness to be vaccinated than younger cohorts. Women are also less likely to want to be vaccinated than men. While observed across all age cohorts, the gender gap is largest among working-age women, and could be driven by gender-specific concerns about side effects, differences in access to information, trust in healthcare systems, or risk tolerance (e.g., Croson and Gneezy, 2009; Dabla-Norris et al., 2021).

As in the case of previous vaccines, concerns about the safety and efficacy of the COVID-19 vaccine have the largest direct impacts on vaccination intent. Respondents who strongly believe that the government will provide them with an effective vaccine are almost 50 percentage points more likely to take the vaccine than those who do not. Similarly, respondents who express strong concerns about side effects are 30 percentage points less likely to take the vaccine than those who do not. This suggests that public health policies and communication targeted at informing the public about vaccine safety and effectiveness are key to containing vaccine hesitancy.

The decision to be vaccinated against COVID-19 is also shaped by interactions with peers. People who are more exposed to warnings against the vaccine from family and friends are also less willing to take it, and more likely to share negative information about vaccines with their peers. Quantitatively, a one percentage point increase in the number of friends and family that want the vaccine is associated with a 0.5 percentage point increase in own probability of vaccination, suggesting that vaccine hesitant respondents tend to cluster across the same social networks.

Lastly, we assess the effects of vaccine hesitancy on the number of COVID-19 cases and deaths in an extended SIR model. The model accounts for several relevant features of the COVID-19 pandemic, including endogenous infection rates, asymptomatic transmission, random testing and vaccines. We introduce vaccine hesitancy into the model by changing rollouts in two ways: (i) imposing a cap on the share of population that gets vaccinated; and (ii) reducing the number of vaccinations administered each day, as demand for vaccines fails to meet supply (including due to vaccine shopping) and doses go unused. When both effects are at play, vaccine hesitancy can have a large impact on excess deaths from COVID-19. For example, a counterfactual exercise which increases vaccine hesitancy in the United Kingdom (the lowest in our sample) to the levels observed in France (the highest in our sample) could have worsened the death toll in the United Kingdom by approximately 18,000 deaths between February and July 2021.

In contrast, if governments are able to maintain a rapid pace of vaccine rollouts so that the only effect of vaccine hesitancy is to cap the number of people vaccinated in line with the levels of 
vaccine hesitancy measured in our survey, our model predicts that number of excess deaths would be almost 20 times lower. This is because the consequences of a slower rollout compound over time, resulting in much larger effects than what would be expected if the population were quickly vaccinated. The policy benefits of increasing vaccination speed are therefore significant, as it decreases both cumulative deaths, time to herd immunity, and risk of new variants. At the same time, it is also important to take action to reduce hesitancy, especially if the share of population that is willing to be vaccinated is lower than the levels needed for herd immunity.

\subsection{Relationship to the Literature}

Our paper is part of a growing literature that examines the drivers of behavioral responses to COVID-19, including whether or not to get vaccinated. ${ }^{3}$ Using an online survey of 6 European countries conducted in April of 2020, Neumann-Böhme et al. (2020) and Bughin et al. (2021) argue that vaccination preferences are shaped by individual perceptions of benefits and risks, which in turn depend on information from peers and trusted institutions. Lazarus et al. (2021) also find large cross-country heterogeneity in vaccine hesitancy in surveys completed in June of 2020, with higher acceptance rates in countries with stronger trust in government. Much of this research focuses on just a few advanced economies and surveys conducted while COVID-19 vaccines were still being developed. We contribute by analyzing a richer dataset covering 17 countries that begins around the time the first vaccine efficacy results were announced, allowing us to explore how hesitancy has changed as mass vaccination programs were rolled out.

An extensive pre-pandemic literature links lower vaccine take-up with vaccine mistrust, concerns about potential side effects, and inconsistent risk messages from experts and elected officials (Das and Das, 2003; Martinez-Bravo and Stegmann, 2021). ${ }^{4}$ These factors are also important for COVID-19 vaccines, with recent work showing that misinformation and conspiracy theoriesespecially when crafted in pseudo-scientific language-significantly impacts COVID-19 vaccine acceptance (Thunström et al., 2020; Loomba et al., 2021). ${ }^{5}$ Hesitancy also appears to be

\footnotetext{
${ }^{3}$ Another strand of the literature looks at compliance with social distancing recommendations, and finds that it is associated with a range of socio-demographic characteristics and personal attitudes (Dabla-Norris et al, 2021, Galasso et al., 2020), as well as other factors such as work flexibility (Papageorge et al., 2020), political beliefs (Allcott et al., 2020; Barrios and Hochberg, 2020), risk preferences (Fan et al., 2020), media choices (Simonov et al., 2020), and civic capital (Barrios et al., 2021).

${ }^{4}$ Omer et al. (2009) and Sadaf et al. (2013) provide useful reviews of the medical literature on this topic, while Dupas and Miguel (2017) offer a useful review of the determinants of broader health care demand, especially in developing countries.

${ }^{5}$ Carrieri et al. (2019) show that misinformation about MMR vaccines led to a reduction in child immunization rates in Italy, especially among households with more online access, while Du et al. (2020) argue that news about manufacturing malpractices was linked to increased hesitancy about vaccination in China. In fact, events that erode trust can impact healthcare demand beyond vaccinations. For instance, Alsan and Wanamaker (2018) show that the disclosure of the Tuskegee study is linked to increases in medical mistrust and mortality and decreases in both outpatient and inpatient physician interactions for older black men in the US.
} 
connected with social media use, and distrust of traditional and authoritative media sources (Murphy et al., 2021). Our results confirm the importance of trust and peers in driving vaccine acceptance, even after controlling for demographics and perceived risk of COVID-19. We also show that policies that increase trust, in particular by assuaging concerns about potential side effects, can have a dramatic impact on vaccine hesitancy, and should be prioritized.

Finally, our paper is related to studies of vaccination policy using epidemiological models. ${ }^{6}$ There is a large pre-pandemic body of work examining the impact of vaccination on the dynamics of infectious diseases-Chen and Toxvaerd (2014) and Rowthorn and Toxvaerd (2020) provide useful reviews. We extend the canonical SIR model to include vaccination policy and hesitancy, building on work by Radzikowski and Dizioli (2021), and use this model to study the potential impact of vaccine hesitancy on COVID-19 dynamics.

The rest of the paper proceeds as follows. Section 2 presents the data and discusses stylized facts about COVID-19 vaccine hesitancy. Section 3 describes the empirical approach and Section 4 examines the different drivers of vaccine hesitancy in our data. Section 5 then studies how hesitancy can impact vaccination programs and draws policy implications. The last section concludes.

\section{Data and stylized facts}

\subsection{Data sources}

Our main data source is the COVID-19 behavior tracker, a publicly available survey developed by YouGov and the Institute of Global Health Innovation (IGHI) at Imperial College London. Since the start of the pandemic, this tracker has interviewed tens of thousands of people per week across several countries to gather global insights on people's behaviors in response to COVID-19.

The tracker covers a wide range of questions on COVID-19 symptoms, testing, attitudes, and compliance with social distancing recommendations (see Dabla-Norris et al., 2021). Each survey wave is designed to be broadly representative of the general public in each country, and typically has around 1,000 respondents.

For this paper, we focus only on survey waves with information on attitudes towards COVID-19 vaccines. These waves were mostly conducted bi-weekly between November 2020 and April 2021 , and span over 114,000 individual observations. Data on vaccine attitudes is available for 17 countries, although with a slight change in country coverage over time, as Finland was replaced

\footnotetext{
${ }^{6}$ A recent literature extends the canonical SIR model to study the interaction between pandemics and economic behavior and social distancing - see, for example, Acemoglu et al. (2020) and Eichenbaum et al. (2021).
} 
by Israel in early 2021, and the United States replaced the Netherlands in March 2021.7 Details on data availability by country and over time are presented in Figure B.1 in the appendix.

Each respondent is asked a number of questions on COVID-19 vaccines. These include whether respondents would take a COVID-19 vaccine if available (or if they've already been vaccinated), how they perceive vaccine effectiveness and potential side effects, and what obstacles they might face to get their shot. The surveys also ask questions about vaccination attitudes among friends and family, and about sharing and receiving information about vaccines from friends and family and online. Individual responses are self-reported, and coded categorically, either has a binary choice ("Yes" or "No"), or on a sliding scale of agreement or importance. Table A.5 in the appendix provides additional details on some of the questions included in the survey.

Our dataset also includes a wealth of controls, including information on location (state or region), gender, age, health, employment status and occupation, household size, and the number of children in the household. It also includes measures of individual attitudes towards COVID-19, as well as confidence in their government's handling of the COVID-19 crisis and the ability of national health systems to respond to the crisis. Finally, we take data on daily vaccinations from the COVID-19 databases compiled by Our World in Data.

\subsection{Vaccine hesitancy across countries and over time}

We measure vaccine hesitancy by looking at whether respondents agree, disagree or are unsure about the statement "I will take the COVID-19 vaccine if it becomes available to me." Across our full sample, only 61 percent agree that they will take the COVID-19 vaccine, while 22 percent are unsure, and 17 percent disagree. However, there is significant variation across countries and over time. Figure 1 plots the share of the population that is willing to take the vaccine by country (averaged across all periods in the sample), which ranges from less 40 percent in France to about 77 percent in the United Kingdom. This suggests that simply shoring up the number of available vaccines without simultaneously increasing vaccine demand could be insufficient to boost immunization rates to the levels required to achieve herd immunity in many countries.

\footnotetext{
7 Our sample covers Australia, Canada, Denmark, Finland, France, Germany, Israel, Italy, Japan, Netherlands, Norway, Singapore, Republic of Korea, Spain, Sweden, United Kingdom, and the United States. The data can be downloaded from https://github.com/YouGov-Data/covid-19-tracker/
} 


\section{Figure 1: Variation in vaccine hesitancy across countries}

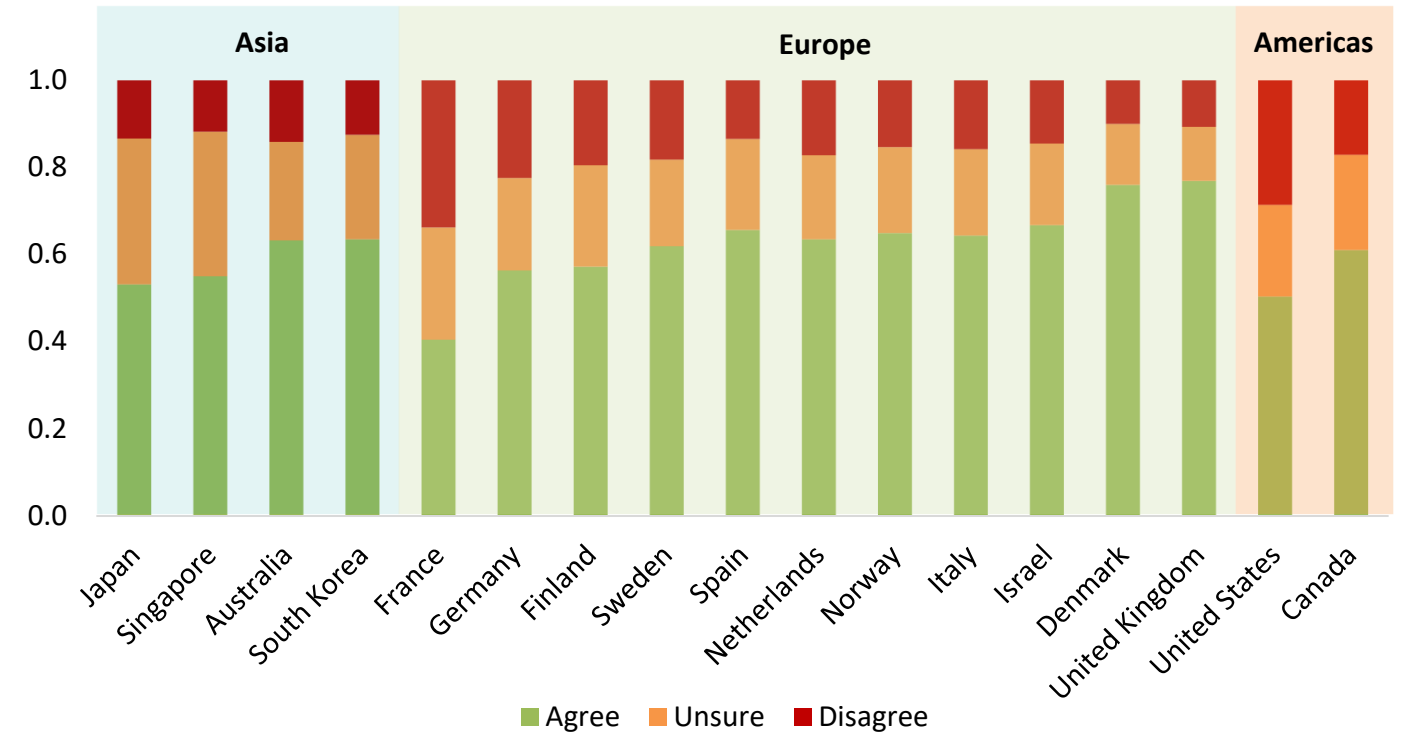

Note: This figure shows average responses to the question of whether respondents agree, disagree or are unsure about the statement "I will take the COVID-19 vaccine if it becomes available to me." We average responses across all waves available for each country.

There is also considerable regional variation in vaccine hesitancy in many countries. To illustrate this point, Figure 2 plots average vaccine hesitancy across German states and regions in the United Kingdom (the nine regions in England, plus Scotland, Wales and Northern Ireland). There are clear and significant regional differences in willingness to take the vaccine in Germany and in the United Kingdom, although the variation is much smaller in the latter. This suggests that even countrywide acceptance of COVID-19 vaccines may not be sufficient when associated with high vaccine rejection rates at the local level. Indeed, if vaccine refusers cluster geographically or share the same social networks, achieving herd immunity is more challenging. This is because the clustering of people that are not immunized can disproportionately increase the percentage of vaccination coverage required to achieve herd immunity in neighboring regions or networks.

It is also important to bear in mind that vaccine hesitancy is not exclusive to the COVID-19 vaccines. In fact, Figure 3 suggests that the level of hesitancy to the COVID-19 vaccine in most countries tracks hesitancy for all other vaccinations. The vertical axis in the figure shows the average share of the population that strongly agrees that vaccines are safe, that they are important and that they are effective. These shares were computed based on data collected by Figueiredo et al. (2020) between 2015 and 2019 and predate the current pandemic. The horizontal axis measures the share of the population who strongly agrees that they will take the COVID-19 vaccine if available. General vaccine hesitancy is strongly and positively correlated with COVID-19 vaccine hesitancy across countries. 
Figure 2: Variation in vaccine hesitancy within countries: UK and Germany

UK

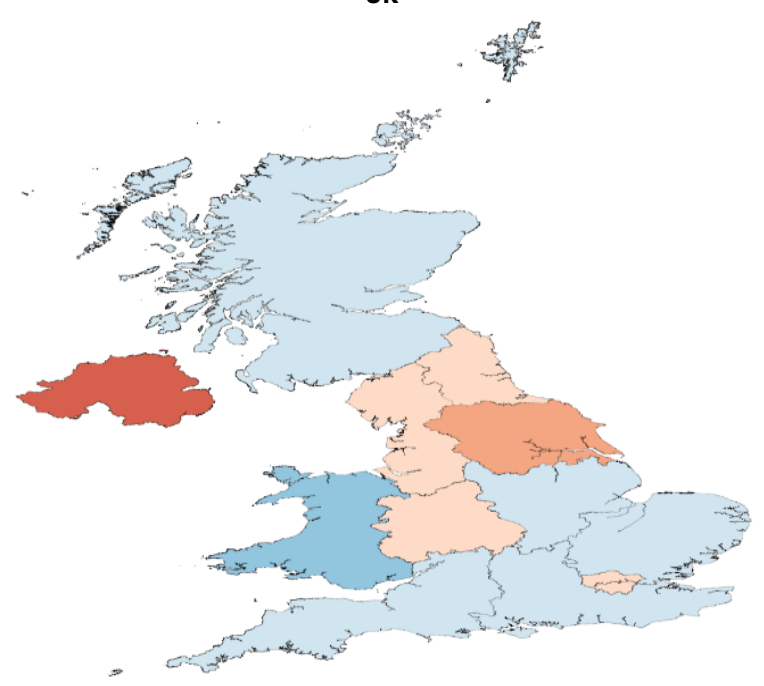

Germany

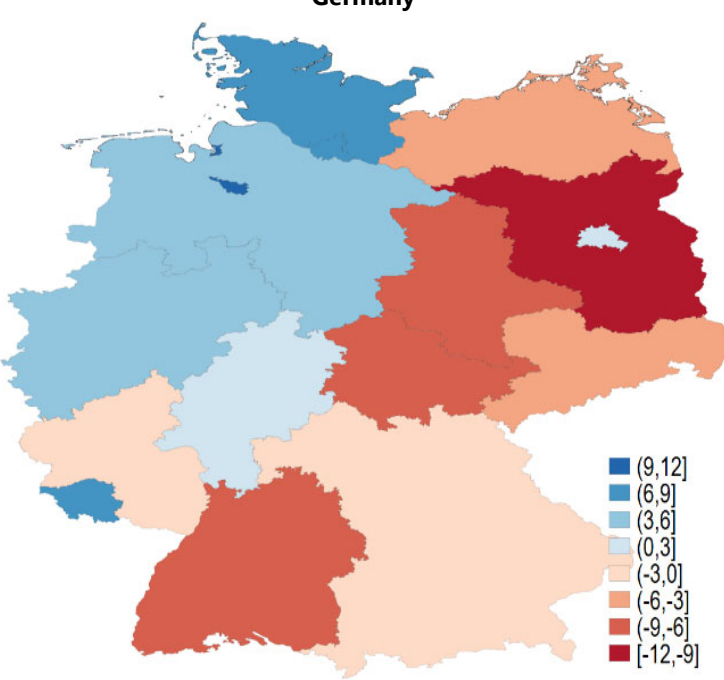

Note: This figure computes share of the population that agrees with the statement "I will take the COVID-19 vaccine if it becomes available to $m e^{\prime \prime}$ across regions and plots the deviation from the country mean in percentage points. For example, regions in dark blue are 9-12 p.p. more likely to take the vaccine than the average citizen in the country. We average responses across all waves available for the UK and Germany.

\section{Figure 3: General vaccine acceptance and COVID-19 vaccine intent}

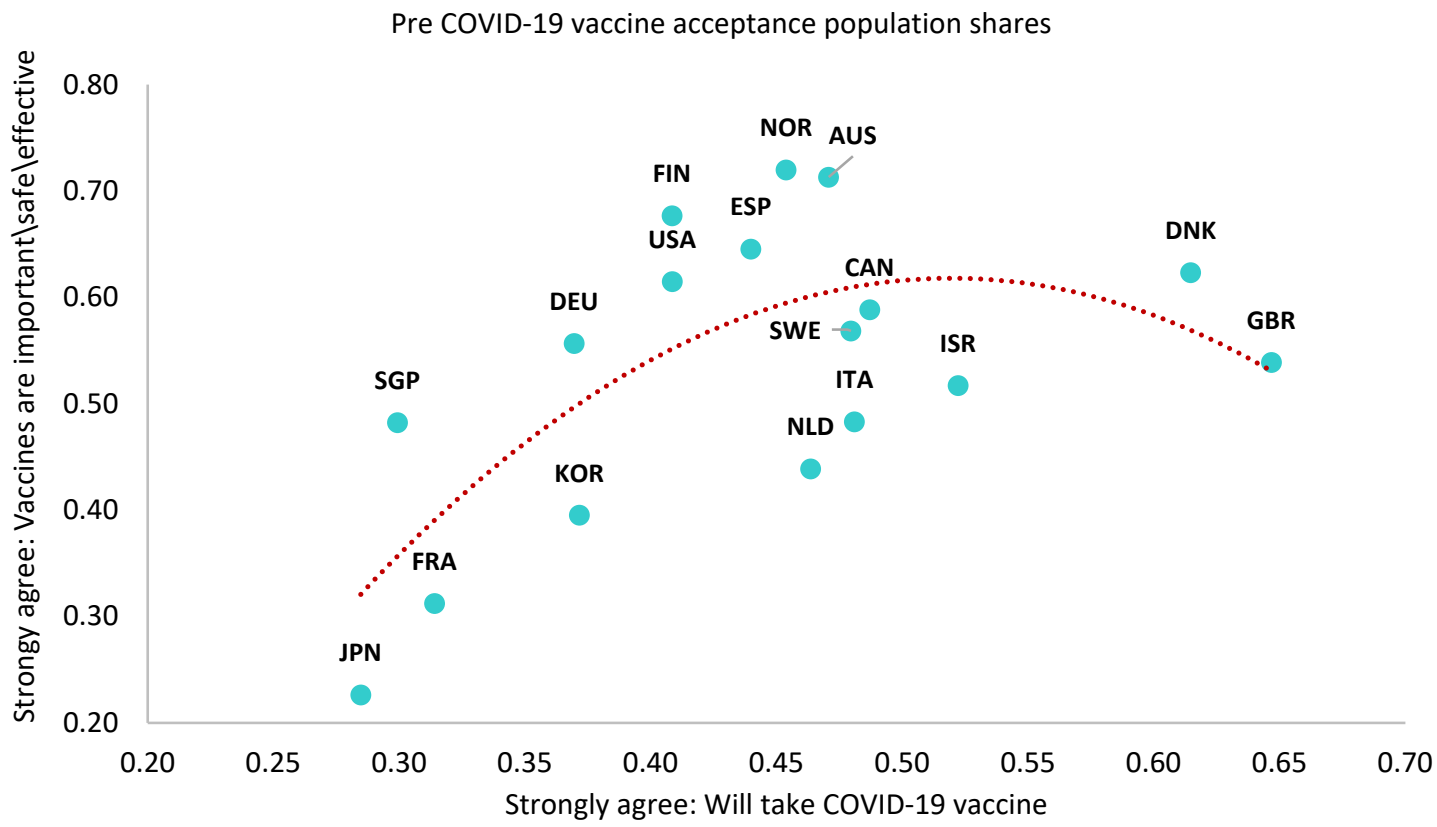

Note: This figure plots the country share of respondents who strongly agree with the statement "I will take the COVID-19 vaccine if it becomes available to me" against the share of people who strongly agree that vaccines are important, safe and effective. This second indicator is taken from Figueiredo et al. (2020).

However, Figure 3 also shows that some countries seem to have been able to reduce hesitancy for the COVID-19 vaccine past the level that would be expected given hesitancy for other 
vaccines. This is encouraging and suggests that reducing vaccine hesitancy is possible. In fact, and despite the high levels of COVID-19 vaccine hesitancy observed in many countries, our data suggests that skepticism about COVID-19 vaccines has broadly declined over time, with the start of the decline coinciding with vaccine approval and rollouts. The speed of decline is heterogeneous across countries, but the trends shown in Figure 4 suggest that the countries that started vaccination early (in Europe and North America) have experienced a faster decline in hesitancy over time. This suggests that vaccine hesitancy can be lowered and demands further investigation to uncover what actions should be taken to achieve that goal. We turn to this question in the next section.

\section{Figure 4: Trends in COVID-19 vaccine demand over time}
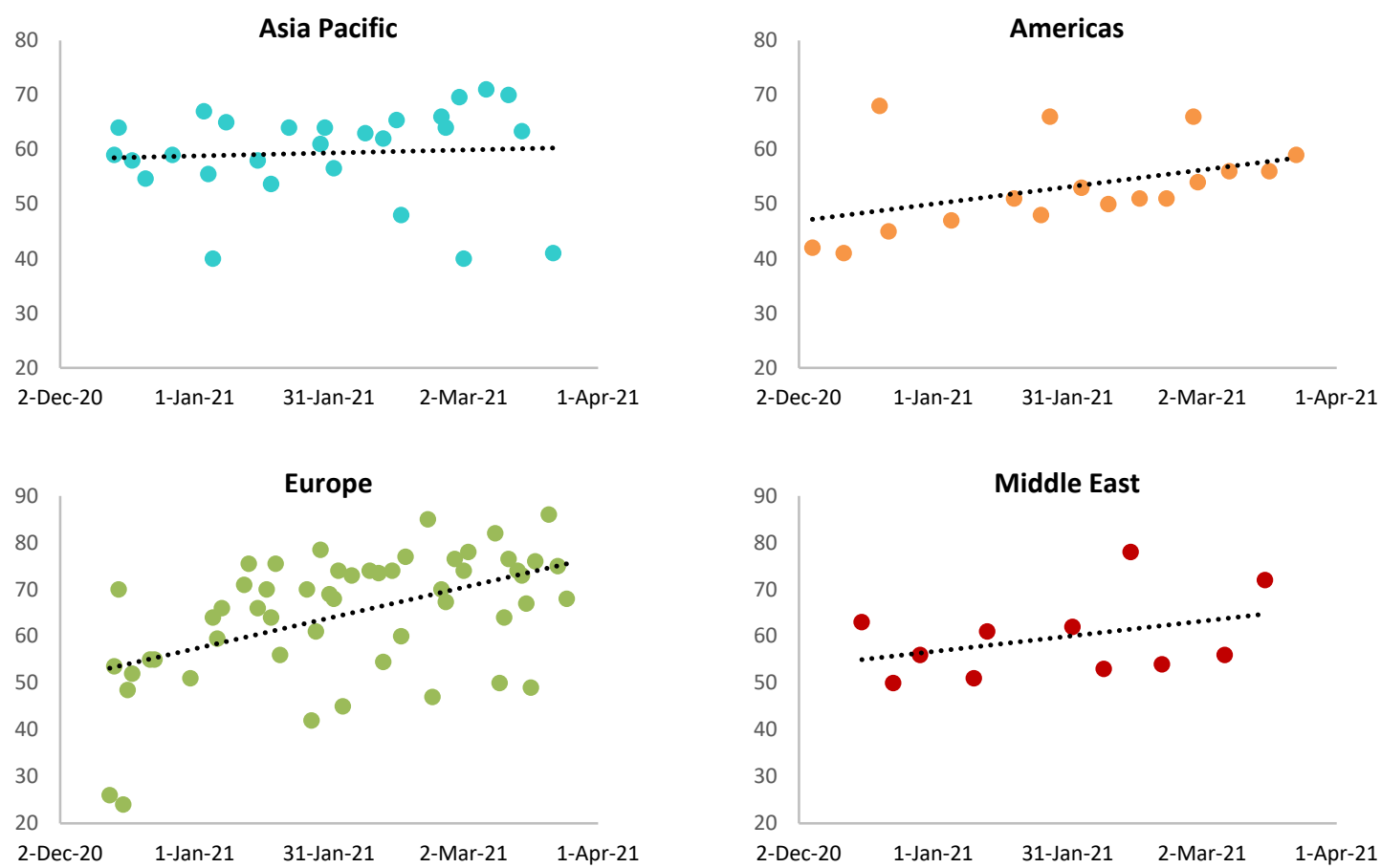

Note: This figure shows the average share of the population that will take the vaccine (or have already done so), plotted against calendar weeks. The regions are defined as follows: Asia Pacific (Australia, China, Hong Kong, India, Indonesia, Malaysia, Philippines, Singapore, Taiwan, Thailand, Vietnam), Americas (Canada, Mexico, USA), Europe (Denmark, Finland, France, Germany, Italy, Norway, Poland, Spain, Sweden, UK) and Middle East (Saudi Arabia, UAE). Data is available at the YouGov COVID-19 Public Monitor: Vaccine Willingness. This is a slightly different dataset, which focuses exclusively on vaccine hesitancy/willingness and thus has a higher coverage than the microdata described in section 2.1.

\section{Empirical Model}

The baseline empirical model examines the impact of perceptions regarding COVID-19, the vaccine itself, and the response of government and health care systems to the pandemic on vaccination intent. We adopt the following linear probability model:

$$
\mathbb{I}\left(\text { take vaccine }_{i(j, t)}\right)=D_{i(j, t)}^{\prime} \beta_{D}+A_{i(j, t)}^{\prime} \beta_{A}+V_{i(j, t)}^{\prime} \beta_{V}+S_{i(j, t)}^{\prime} \beta_{S}+G_{i(j, t)}^{\prime} \beta_{G}+\delta_{j, t}+\varepsilon_{i(j, t)}
$$


where $\mathbb{I}\left(\right.$ take vaccine $\left._{i(j, t)}\right)$ is an indicator that assumes a value of 1 if individual $i$ in location $j$ (states or regions within a country) and date $t$ agrees to take the COVID-19 vaccine if available and 0 if she does not. ${ }^{8}$ In our main specification (1), we focus on respondents that agree or disagree that they would take the vaccine if available, and exclude respondents that are unsure. In the robustness section, we estimate an alternative model that compares unsure respondents with those that agree to take the vaccine. Our baseline model also favors a linear probability specification, due to the ease in interpreting coefficients and because of the large number of fixed-effects (location-by-time) that are included. The robustness section also discusses an alternative logit specification of the same model. Our findings are consistent across all specifications.

The vector of controls $D_{i}$ contains demographic variables, consisting of age cohort, gender, household size, number of children, and occupation. ${ }^{9}$ We also include indicator variables capturing pre-existing health conditions that may increase COVID-19 risk, and whether individuals have experienced COVID-19-related symptoms.

Next, $A_{i}$ measures self-reported ease of access to a vaccination site. Some of the reasons indicated by respondents explaining why access might be difficult include: vaccination sites are too far from where they live, or are open in inconvenient times; they are not able to go to a site by themselves; the waiting times at a vaccination are too long; and they fear they might be turned away from a site without receiving the vaccine. Our measure aggregates all those issues into a single dummy variable that indicates whether or not individuals think it would be hard to get a COVID-19 vaccine.

$V_{i}$ includes the responses to questions about COVID-19 and perceptions about the safety and efficacy of vaccines. These questions ask participants to indicate how worried they are about COVID-19 and about the potential side-effects of the vaccine. They also indicate how confident they are that their government will provide them with an effective vaccine.

Compliance with social distancing recommendations is captured by $S_{i}$. For simplicity, we aggregate all questions in that regard into two categories, including compliance with safe behaviors and mask wearing. Safe behaviors include handwashing frequency, and whether individuals follow health authorities' advice and practice social distancing. Mask wearing summarizes how diligent people are about wearing masks outside their home. Since each category includes multiple questions, we summarize the data by assigning a sliding scale to each

\footnotetext{
${ }^{8}$ We assume that that $i$ agrees to be vaccinated if she answered "4- Agree" or " 5 - Strongly Agree" to the question "If a Covid-19 vaccine becomes available to me in 2021, I definitely intend to get it." Alternatively, if she answered "1 - strongly disagree" or "2 - disagree" to that question, the indicator takes the value of zero.

${ }^{9}$ We break age into separate groups (18-24, $25-34,35-44,45-54,55-64,65-75$, and $\left.75+\right)$ to capture potential non-linear effects.
} 
answer (with 1 representing "strongly disagrees" and 5 meaning "strongly agrees") and computing the share of the possible total that each individual obtained. This provides an index between 0 and 1 that describes how much each person has adhered to the safety recommendations.

Finally, $G_{i}$ includes information on the extent to which individual $i$ trusts their government. It consists of two questions: "how well or badly do you think the government is handling COVID-19" and "how much confidence do you have in the healthcare system to respond to COVID-19". To abstract from time and spatial variation in COVID-19 transmission dynamics and related policy interventions (e.g., stringency of government lockdowns), all regressions condition on locationby-week fixed effects, $\delta_{j, t}$. The results of the estimation are discussed below (see also Table A.1).

\section{Results}

For ease of exposition, we classify our variables into two groups: demographic characteristics and vaccine access, and beliefs concerning COVID-19, vaccines and trust in government, which can potentially be affected by policy and/or new information. The results below all use regression model described in equation (1) and include the full set of controls. All standard errors are clustered at the country level.

\subsection{Demographic characteristics and Vaccine access}

We first examine how vaccine hesitancy varies with age and gender. We estimate the average age profiles in the probability of vaccination among men and women, across all countries in our sample. These profiles are plotted in the left panel of Figure 5.

Age is an important driver of vaccine intent and older people are much more willing to get vaccinated against COVID-19. This is not entirely surprising, since COVID-19 mortality and morbidity increases exponentially with age (Levin et al., 2020; O'Driscoll et al., 2020), and the initial public health messaging on vaccines focused heavily on raising awareness and building trust among older individuals. We would therefore expect vaccine hesitancy to decrease with age, and especially so for the oldest cohorts.

In addition, we find that women are less likely to want to be vaccinated compared to men. This gender gap is observed across all age cohorts, and is consistent with previous findings on hesitancy towards COVID-19 vaccines (e.g., Paul et al., 2021; Neumann-Böhme et al., 2020). The gap largely reflects a higher proportion of women being unsure about their vaccine intent, with smaller gender differences among those who outright reject vaccination. This could have multiple drivers, including specific concerns about side effects among women, gender differences in access to information, trust in healthcare systems or risk aversion. However, it is unlikely to be explained by women perceiving a lower risk of COVID-19, since women in the same survey also 
report higher rates of compliance with social distancing recommendations (Dabla-Norris et al., 2021).

Figure 5: Impact of age, gender, and occupation on the probability of vaccination
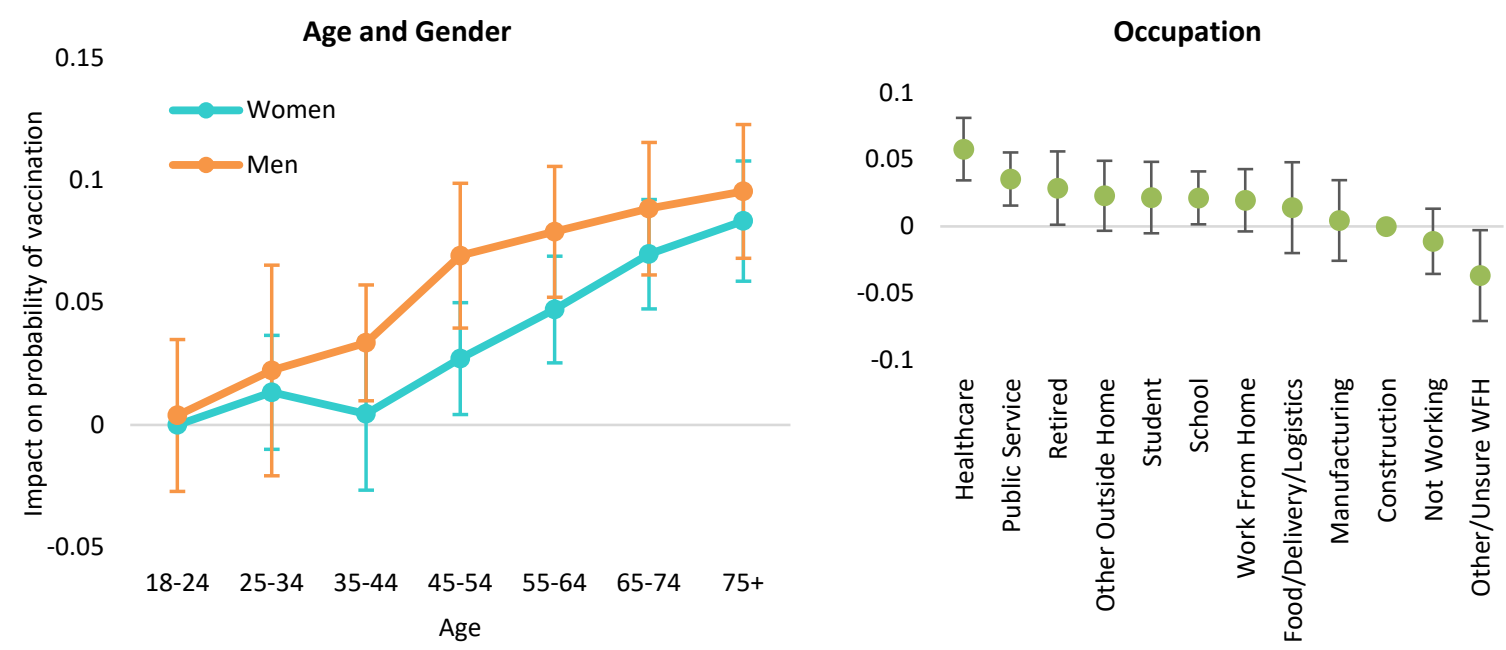

Note: The left panel shows the impact of age and gender on the probability of vaccination, relative to the cohort of 18 to 24 year old females. The right panel shows the effect on the likelihood of vaccination by employment sector, in percentage points. Coefficients are estimated based on equation (1), including all controls and location and week fixed effects. The 95 percent confidence intervals are computed using robust standard errors clustered by country.

We also examine differences in compliance across employment sectors. We start by restricting the analysis to full and part-time workers, separating between those working from home from those who are not able to telework. Among the latter, we also have information on the sector they work in. We continue to use the specification described in equation (1), and control for age, gender, household composition, and health status. As shown in the right panel of Figure 5, the effect of occupation on the probability of vaccination can be quite large. Controlling for all other characteristics, healthcare workers are the most likely occupation to want to take the vaccine, followed by public servants (essential workers) and the retired. This is potentially good news given that they are the most exposed and the first to be vaccinated in most countries.

Having easy access to a vaccination site also increases the chances that a person gets the vaccine by 4 to 12 percentage points, depending on the model specification. About 55 percent of respondents in our sample report some obstacle to get to a vaccination site. The most common concerns are that the waiting times at vaccination sites are too long (11 percent of respondents), that the sites are too far ( 6 percent), and that they are open during inconvenient times (4 percent). About 6 percent of respondents also fear that they might be turned away from a vaccination site without receiving a vaccine.

\subsection{Beliefs Concerning COVID-19, Vaccines, and Trust in the Government}


Next, we turn to the relation between vaccine intent and attitudes towards COVID-19. Anecdotally, concerns about catching COVID-19 play a significant role in determining the probability of vaccination, suggesting that actual or perceived risk of COVID-19 is a major driver of vaccine intent. This is confirmed by the results in the left panel of Figure 6 . The probability that a person who strongly agrees with the statement "I am worried about getting COVID-19" takes the vaccine is more than 20 percentage points higher than a person who strongly disagrees with it. Similarly, individuals that wear masks and comply with social distancing guidance are also more likely to want to take the vaccine. Each of these variables likely reflects (and partly controls for) risk attitudes and individual beliefs about the severity of the disease.

\section{Figure 6: Probability of vaccination and perceptions of COVID-19}
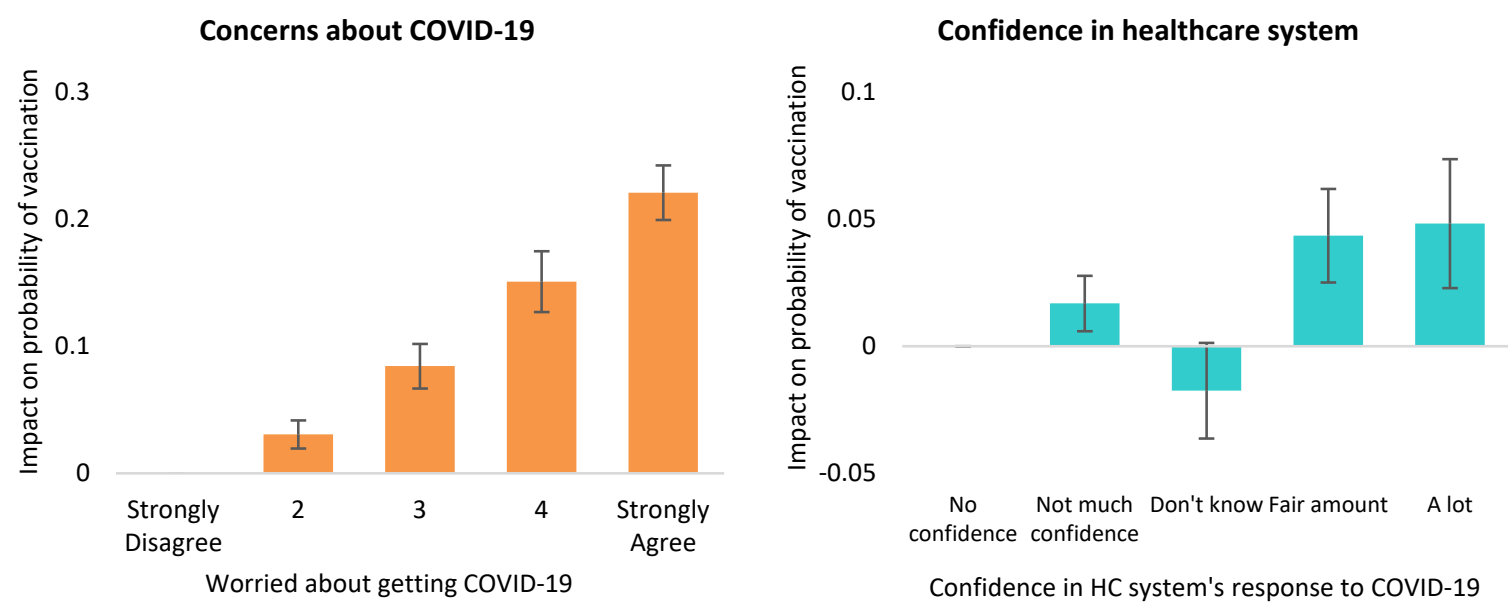

Note: The left panel shows impact of respondents' concerns about COVID-19 on their probability of vaccination. The right panel plots the same effects, this time based on respondents' trust in their nation's healthcare system. Each panel plots the effect on vaccination relative to the lowest category of the survey. Coefficients are estimated based on equation (1), including all controls and location and week fixed effects. The 95 percent confidence intervals are computed using robust standard errors clustered by country.

We also examine how vaccine hesitancy varies with respondents' confidence in the ability of the country's health system ability to respond to COVID-19 crisis. We continue to use the specification in equation (1). Therefore, our results are based on cross-individual variation in selfreported trust, relative to a location-week specific average. This helps to attenuate concerns about omitted variable bias, including from potential differences in the quality of trust questions across countries. The right panel in Figure 6 shows that trust in the capacity of the healthcare system to respond to COVID-19 increases the probability of vaccination by up to 5 percentage points.

Finally, we plot in Figure 7 the impact of the two variables with the largest effects on the probability of vaccination against COVID-19: concerns about the vaccine side effects and whether people believe that their government will provide them with an effective vaccine. These variables have been previously found to impact demand for other vaccines, so it is not surprising that they explain a significant share of the variation in COVID-19 vaccine intent across individuals (Das and 
Das, 2003; Martinez-Bravo and Stegmann, 2021). However, the magnitude of the impacts on vaccine hesitancy during COVID-19 is notable. Widespread concerns about side effects reduces vaccination intent by about 30 percentage points, conditional on controls, while strong trust that the government will provide an effective vaccine increases vaccine demand by almost 50 percentage points relative to those with no trust at all. Importantly, both variables can potentially be shaped by public health policies and communication to inform the public about existing evidence on vaccines.

Figure 7: Probability of vaccination, side effects and effectiveness

Side Effects

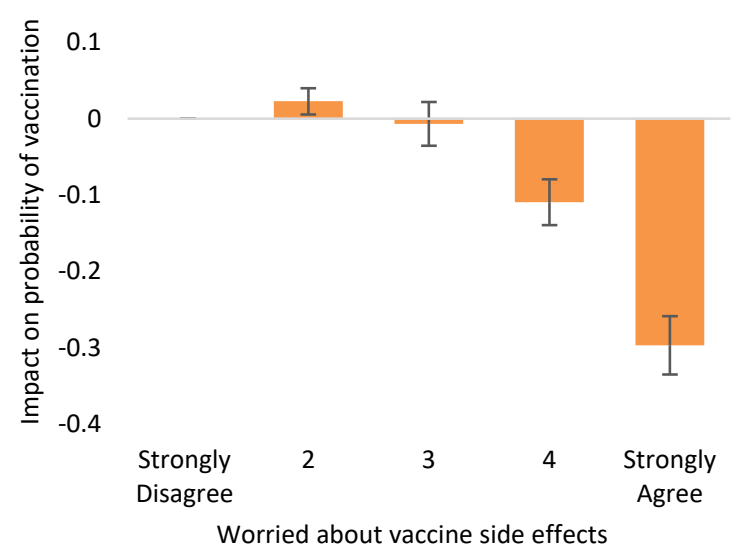

Effectiveness

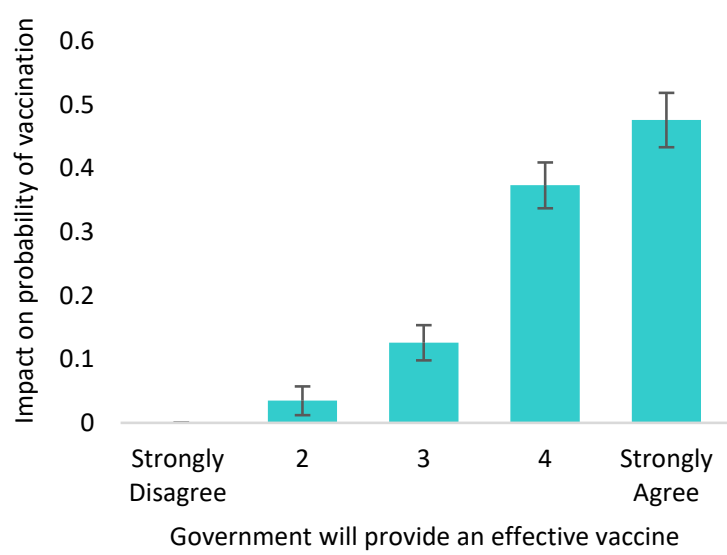

Note: The left panel shows the impact of respondent's concerns about vaccine side effects on their probability of vaccination; the right panel shows the same effects based on the confidence that their government will provide an effective vaccine. Each panel plots the effect on vaccination relative to the lowest category of the survey. Coefficients are estimated based on equation (1), including all controls and location and week fixed effects. The 95 percent confidence intervals are computed using robust standard errors clustered by country.

\subsection{Peer Effects and Information}

Another factor that can potentially influence an individual's decision to be vaccinated against COVID-19 is whether their peers are doing so as well. Evidence suggests that there are significant peer effects on vaccination through various mechanisms such as information sharing and imitation (Rao 2007; Bodine-Baron et al., 2013; Sato and Takasaki 2019). One particularly important mechanism in the context of the COVID-19 vaccines is the quantity and quality of information that people have access to. People that are more exposed to warnings against the vaccine from their peers could also be less willing take the shot. Conversely, someone who has reservations against the vaccine could also be more likely to look for negative information about in and share it with their peers. The results plotted in Figure 8 suggest that both these channels seem to play a role on vaccine hesitancy.

Vaccine rollouts could also influence uptake. In countries with faster rollouts, the likelihood that people know someone who has received the vaccine is higher, and network effects could play a role in shaping intent. In addition, faster vaccine rollouts provide more data on vaccine side 
effects. If the number of people experiencing adverse side effects is consistently small, concerns about uptake could taper off.

Figure 8: Misinformation and vaccine hesitancy

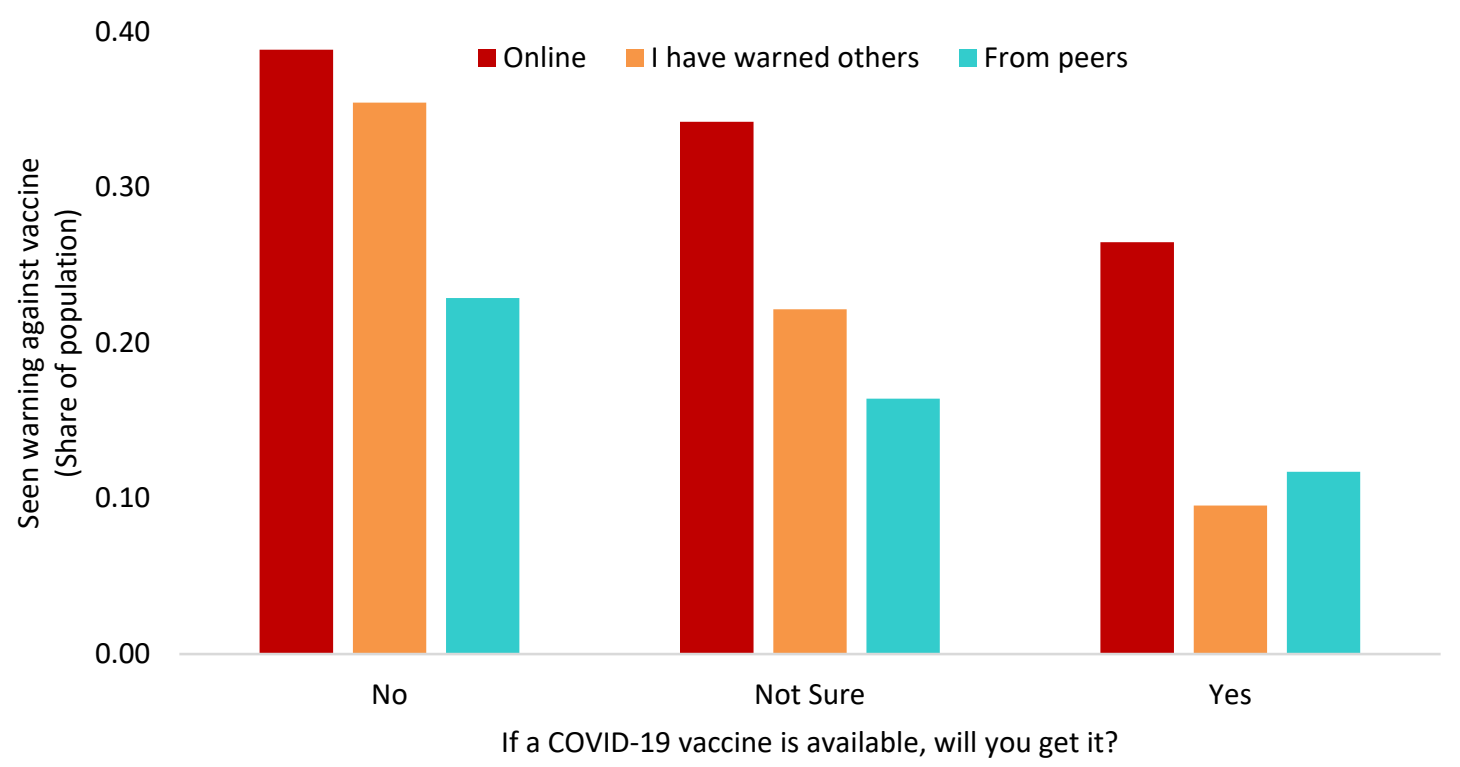

Note: This figure plots the average share of respondents who have seen warnings against the COVID-19 from different sources (online or peers), or that have shared similar warnings themselves. The shares are plotted separately depending on whether respondents agree, disagree or are unsure about taking a COVID-19 vaccine themselves if available.

To measure the effect of the vaccination rollout, we include the log of vaccinations per 100 people in individual $i$ 's country at date $t$ into equation (1). We also change the fixed effects from location-by-week to location and week $\left(\delta_{j}+\delta_{t}\right)$ to capture the impact rollouts on vaccine intent. Measuring the impact from peer effects on the probability of vaccination is more challenging, as the network of one's peers is most likely endogenous. One naïve approach is to include the percentage of each respondent's close friends and family that will take the vaccine as a measure of peer effects (the endogeneity issue comes from the fact that individual $i$ wanting to be vaccinated makes it more likely that their friends and family are like-minded).

Table A.2 in the appendix shows the results of this regressions. Columns (1) - (4) mimic Table A.1, with the addition of the vaccination rollout as a control. Note that the rollout has a positive and significant effect on the probability of vaccination in columns (1) and (2) which only include demographic variables. Once concerns about side effects and the effectiveness of the vaccines are controlled for (columns 3 and 4), the effect of the rollout becomes considerably smaller and is no longer statistically different from zero. The effects of the other variables are largely in line with Table A.1.

Columns (5) of Table A.2 includes the share of friends and family than plan to take the vaccine as a measure of peer effects. In this specification, peer effects are strongly correlated with the 
probability of vaccination: a one percentage point increase in the share of friends/family that will take the vaccine is associated with a 0.5 percentage point increase in the probability of vaccination. However, this coefficient could be biased upwards for the reasons mentioned above.

Comparing columns (4) and (5) in Table A.2 we find that peer effects as an explanatory variable attenuates the size of other coefficients, but the effects retain their directions. While this result is hard to interpret, given the endogeneity of peer effects noted above, it suggests that the effects that were found in the previous section are qualitatively robust to network and peer effects.

\subsection{Robustness}

Uncertainty about vaccines. Individuals that do not want a vaccine and those who are unsure about getting one if available could have different motivations. As a result, we estimate two separate models. The baseline (discussed above) compares people who will take the vaccine with those that will not. An alternative model compares those who will take the vaccine with those that are unsure about it. Both models are described by equation (1), with the only difference being how we define the dependent (left-hand side) variable.

Qualitatively, the results in both models are very similar. Quantitatively, the effects estimated in the alternative unsure model tend to be smaller. This suggests that the same concerns determine vaccine hesitancy for both the unsure and the people who refuse vaccines. The difference between them is the extent to which these concerns outweigh the potential benefits of the vaccine. The coefficients for the alternative model are reported in Table A.3.

Latent Variable Logit Model. In our main specification, we favor the linear probability model due to the ease of interpretating its coefficients. One drawback of this model is that the predicted probabilities of vaccination can be smaller than zero or greater than one (although this happens for only 4 percent of observations). As an alternative, we adopt a "latent variable" interpretation of the data and construct a logit model for the probability of vaccination.

Suppose that individual $i$ computes the net benefit of taking a vaccine, $y_{i}^{*}$, based on the following equation

$$
y_{i(j, t)}^{*}=D_{i(j, t)}^{\prime} \beta_{D}+A_{i(j, t)}^{\prime} \beta_{A}+V_{i(j, t)}^{\prime} \beta_{V}+S_{i(j, t)}^{\prime} \beta_{S}+G_{i(j, t)}^{\prime} \beta_{G}+\delta_{j}+\delta_{t}+v_{i(j, t)}
$$

where the matrices on the RHS represent the same data as in equation (1) and $v_{i}$ has a standard logistic distribution. ${ }^{10}$ In this case, individual $i$ will take the vaccine if $y_{i}^{*} \geq 0$ and will not take the vaccine if $y_{i}^{*}<0$. We do not directly observe $y_{i}^{*}$, but $\mathbb{I}\left(y_{i}^{*} \geq 0\right)$ is known and can be used to

\footnotetext{
${ }^{10}$ We also adopt "location plus time" fixed effects, instead of "location by time". This is done to reduce the number of incidental parameters (dummies) that need to be estimated in the model, which could bias our coefficients.
} 
estimate the coefficients in the equation above. Table A.4 in the appendix presents the odds ratios associated with the variables in our model. Once again, the results are consistent with our baseline.

\subsection{Policies to Decrease Vaccine Hesitancy}

We start this section by pointing out that some of the variables included in our empirical model could be endogenous. Our estimates, therefore, might not reflect causal effects and should be interpreted with this caveat in mind. Nevertheless, the regression coefficients are consistent across various model specifications and the inclusion of numerous control variables, including location-week fixed effects to control for country- and region-specific changes in the propensity of vaccination week-by-week. As such, we believe they can still be informative some of the underlying reasons for vaccine hesitancy.

As mentioned above, one of the variables with the largest impact on the propensity to take the COVID-19 vaccine is concern about the potential side effects of the vaccine. It is not uncommon to hear concerns about that vaccines were "rushed" and that more testing is needed. In addition, a large share of the available information that cautions against the use of the vaccine (especially online) is either at odds with scientific evidence or overemphasizes potential side effects. ${ }^{11}$ This type of information can lower the willingness to get the vaccine. It is important, therefore, that health authorities accurately and repeatedly inform the public about the evidence on the safety of vaccines, and address some of their salient concerns. This can have positive peer effects as well. For instance, if a person's vaccination decision is positively influenced by his or her peers' vaccination behavior, interventions to promote vaccine take-up among selected individuals not only directly encourage their own take-up but also indirectly encourage take-up among peers.

The second variable with a strong relationship to the propensity of vaccination is whether or not people think that their government will provide them with an effective vaccine. This question speaks to at least three issues: trust that the government will be able to secure and distribute a vaccine; that the vaccine will be provided to them (and at reasonable cost); and that the vaccine will be effective in tackling infection and transmission of the COVID-19 virus (Figure 9).

\footnotetext{
11 Note that this is not an issue restricted to on-line message boards or chat groups. In first half of March 2021, more than a dozen European countries temporarily halted the use of one COVID-19 vaccine because of a fear that it might cause potentially fatal blood clots in rare cases. This decision was made despite statements by the World Health Organization and the European Medicines Agency that there was no reason to suspect that the vaccine was unsafe. Source: The Economist, March 2021. "EU countries pause AstraZeneca's covid-19 jab over safety fears." url: https://www.economist.com/science-and-technology/2021/03/15/eu-countries-pauseastrazenecas-covid-19-jab-over-safety-fears, accessed on March 23, 2021.
} 
Figure 9: Trust in government and vaccine effectiveness

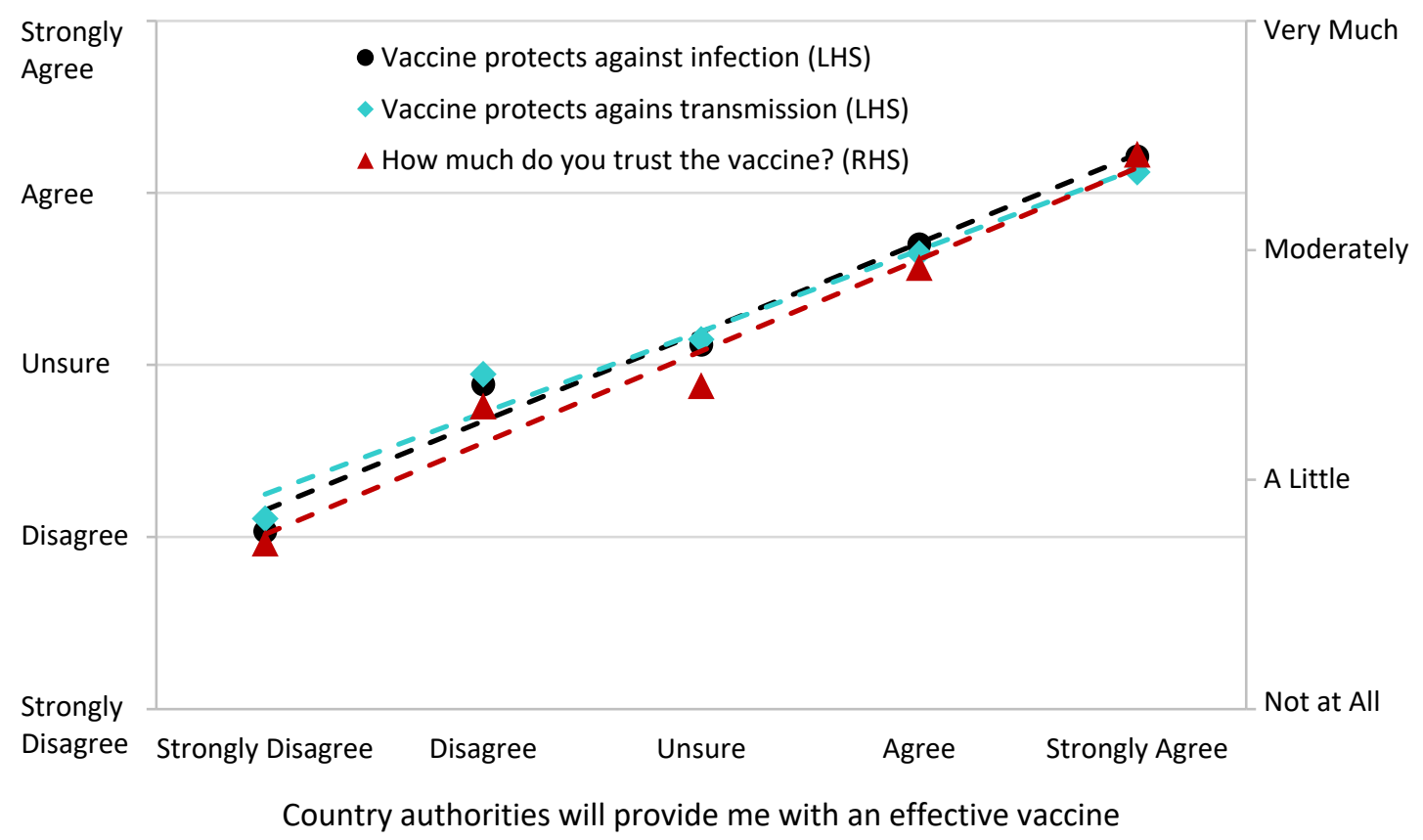

Once again, these correlations suggest that one effective way to reduce vaccine hesitancy is for health authorities to: (i) credibly and regularly inform the public about the vaccine's efficacy as new information becomes available; and (ii) keep updated information about the vaccination rollout (when and where can each person expect to get the shot). Experimental work has also shown the effectiveness of cues and nudges (Milkman et al., 2011) or increased accessibility (Brewer et al. 2017), particularly among those planning to be vaccinated. For those unwilling to be vaccinated, some recent evidence suggests a role for communicating information by diverse individuals, including in terms of expertise (Alsan and Eichmeyer, 2021). By and large, these strategies have already been adopted in some form or another in most countries that have started to vaccinate their population. ${ }^{12}$ Our results and anecdotal evidence given by declining hesitancy (Figure 4) suggest that these approaches could be fruitful.

\footnotetext{
12 This includes the public vaccination of politicians and celebrities, appearances by health experts on various broadcasts (from news casts to YouTube videos) to clarify some of the main misunderstandings, and easy-toaccess and up-to-date web pages in the websites of major hospitals and healthcare organizations containing information on COVID-19 and the vaccines.
} 


\section{Vaccine Hesitancy and the Pandemic Dynamics}

Vaccination is not a goal on itself, but a means to protect people against disease. As such, it is important to gauge how vaccine hesitancy can affect vaccine rollouts, and therefore the speed at which a country's population gains immunity and the consequences in terms of the number of preventable deaths and infections.

\subsection{An Extended SIR Model}

To examine the impact of behavioral choices of individuals and how they interact with the vaccine rollout, we make use of the extended SIR model developed by Radzikowski and Dizioli (2021). The basic framework divides the population $(N)$ into susceptible $(S)$, infectious $(I)$, recovered $(R)$, quarantined $(Q)$, and dead $(D)$. The "quarantined" category is adopted to accommodate asymptomatic transmission and allow for random testing in the model. The difference between people who are infectious and people who are quarantined is that those in quarantine have either developed symptoms or tested positive for COVID-19. As a result, they do not have contact with (and thus do not infect) others.

At each point in time, the population can be partitioned into the five categories mentioned above, so that $N=S_{t}+I_{t}+R_{t}+Q_{t}+D_{t}$. When a share $q$ of the population is tested each day, the laws of motion are:

$$
\begin{gathered}
\frac{d S_{t}}{d t}=\underbrace{-\beta S_{t} I_{t} / N}_{\text {new infections }} ; \\
\frac{d I_{t}}{d t}=\beta S_{t} I_{t} / N-\underbrace{\frac{\gamma}{1-q} I_{t}}_{\text {discover infection }} ; \\
\frac{d Q_{t}}{d t}=\underbrace{-\theta Q_{t}}_{\text {resolving infections }}+\frac{\gamma}{1-q} I_{t} ; \\
\frac{d R_{t}}{d t}=\underbrace{(1-\delta) \theta Q_{t}}_{\text {recovered }} ; \\
\frac{d D_{t}}{d t}=\underbrace{\delta \theta R_{t} .}_{\text {dead }}
\end{gathered}
$$

The parameter $\beta$ measures the rate of infection, $\gamma$ is the rate at which symptoms develop, $\theta$ is the time it takes to recover from an infection, and $\delta$ is the probability of death. The expression $\gamma /(1-q)$ is the rate at which an infected individual discovers that he/she is infected. The reasoning is as follows: once a person is infected, symptoms develop at a Poisson rate $\gamma$, which means that the average number of days until the first symptoms appear is $1 / \gamma$. When a fraction $q$ of the population is tested each day, the average number of days until a person either develops 
symptoms or receives a positive result is $q \times 0+(1-q) \times(1 / \gamma)$. Inverting this expression gives the rate at which infections are discovered.

Following Radzikowski and Dizioli (2021), this framework is extended in several ways, which we discuss below.

Endogenous rate of infection. The rate of infection can change based on behavioral patterns:

$$
\beta_{t}=n_{t} \times \inf _{t} \times \omega_{t}
$$

where $n_{t}$ is the average number of contacts with other people per day (affected by lockdowns and social distancing), in $f_{t}$ is the probability of infection (which can be reduced by wearing masks, washing hands, etc.) and $\omega_{t}$ that adjusts the scale and controls for seasonal differences in the rate of infections. The number of contacts per day is defined as:

$$
\ln \left(n_{t}\right)=\ln \left(n_{0}\right)-m_{t}
$$

where $n_{0}$ is the initial number of contacts and $m_{t}$ is relative mobility in day $t$, measured in relation to the pre-pandemic baseline. Similarly,

$$
\text { inf } f_{t}=\beta_{0} e^{-\lambda t}+\beta_{s}\left(1-e^{-\lambda t}\right)
$$

where $\beta_{0}$ is the initial rate of infection, $\beta_{s}$ is the rate of infection when safety precautions are taken, and $\lambda$ measures the time to make that transition.

Population subgroups and mutant strains. The model also allows for the population to be subdivided into vulnerable and non-vulnerable (young), who differ in their probabilities of death if infected. This is done by differentiating between the vulnerable and the young in each of the five categories of the population. Importantly, the categories remain related. For example, a susceptible vulnerable person can still be infected by a young person. The differentiation between the vulnerable and young is relevant to capture the dynamics of the pandemics, especially policies that prioritize one of these groups are implemented (e.g., vaccines).

Equally important to capture the dynamics of COVID-19 is the introduction of mutant strains, which are potentially more infectious to humans than the wild virus. Including this into the model requires accounting for infections from both types of the virus, which is reflected by including extra terms for the mutant variant in the law of motion of each category in the population. For example, the law of motion for the susceptible becomes:

$$
\frac{d S_{t}^{v}}{d t}=-\beta_{t} S_{t}^{v}\left(I_{t}^{v}+I_{t}^{y}\right) / N-\beta_{t}^{n} S_{t}^{v}\left(I_{t}^{v, n}+I_{t}^{y, n}\right) / N
$$

where $I_{t}^{v}$ is the number of infectious vulnerable people that are infected with the wild virus and $I_{t}^{v, n}$ is the number of infectious vulnerable people that are infected with the new (mutant) strain 
of the virus (similarly, these categories for the young are represented by $I_{t}^{y}$ and $I_{t}^{y, n}$, respectively). $\beta_{t}^{n}$ is the rate of infection for the new strain, defined as:

$$
\beta_{t}^{n}=\mu \times \beta_{s} \times n_{t} \times \omega_{t}
$$

where $\beta_{s}, n_{t}$ and $\omega_{t}$ are as defined above, and $\mu$ is a constant that captures how much more infectious the new strain is, relative to the wild one.

Vaccines. Vaccination can benefit a susceptible person by generating an immune response that prevents illness/death if they are infected with the virus. It may also reduce the probability that this person, if infected, transmits the virus to other susceptible persons. In the model, vaccinated people do not die if they get infected, and the rate of transmission is $v i=3$ times lower when a susceptible person comes in contact with a vaccinated and infected one. ${ }^{13}$ To accommodate these features, new categories are created for the vaccinated and not infected, vaccinated and infected with the wild strain, and vaccinated and infected with the mutant strain. Each of these categories is also subdivided into vulnerable and young, and the laws of motion are modified accordingly.

Calibration. The parameters in the model are calibrated to capture the evolution of the pandemic in the United Kingdom. The path of vaccinations, number of deaths, and other daily data on the COVID-19 pandemic can be found on the datasets compiled by Our World in Data. In addition, the pre-pandemic number of daily contacts is calibrated using results from the American Community Survey, and relative mobility is available through Google's Community Mobility Reports. Figure B.2 in the appendix shows the predicted path for mobility and number of contacts based on estimates by Radzikowski and Dizioli (2021).

The top panel of table 1 shows the values of the parameters mentioned above. We also include the probability of death (once infected) of the vulnerable $\left(\delta^{v}\right)$ and the young $\left(\delta^{y}\right)$, as well as their population shares $\left(s^{v}\right.$ and $\left.s^{y}\right)$. Those parameters are calibrated by defining the vulnerable population as those aged 65 and over. The bottom panel of table 1 shows the share of the population that is tested in each of the 500 days between February $29^{\text {th }}, 2020$ and July $12^{\text {th }}, 2021$.

\footnotetext{
${ }^{13}$ While this number is still highly uncertain, there is increasing evidence that vaccines can substantially cut the rates of transmission for infected individuals. A recent study by Levine-Tiefenbrun et al. (2021) shows that vaccines can significantly reduce the viral load if an infection occurs, which has been shown to affect the probability of transmission. A Daily Briefing by the Advisory Board published on March $4^{\text {th }}$ also discusses the issue (available at: https://www.advisory.com/en/daily-briefing/2021/03/04/vaccine-transmission).
} 
Table 1: Parameter Values

\begin{tabular}{|c|c|c|c|c|c|c|c|c|c|c|c|}
\hline Parameter & $\beta_{0}$ & $\beta_{s}$ & $\lambda$ & $\gamma$ & $\theta$ & $\mu$ & $v i$ & $\delta^{v}$ & $\delta^{y}$ & $s^{v}$ & $s^{y}$ \\
\hline Value & 0.1658 & 0.0835 & 0.028 & 0.17 & 0.12 & 1.47 & 3 & 0.02473 & 0.00069 & 0.18 & 0.82 \\
\hline Days & $1-14$ & $15-27$ & $28-$ & & & 60 & & 51-101 & & $2-500$ & \\
\hline$q$ & 0 & 0.05 & 0.2 & & & 28 & & 0.3 & & 0.3 & \\
\hline
\end{tabular}

\subsection{Adding Vaccine Hesitancy}

Vaccine hesitancy can affect vaccination efforts in two ways. First, it introduces a cap in terms of the number of people who will get the vaccine, which can be below the required threshold needed to achieve herd immunity. Second, it can reduce the average number of people getting vaccinated per day, for example when a low uptake of the vaccine leaves doses unused or discarded..$^{14}$ We introduce each of those outcomes in the model by changing the number of vaccines delivered per day, relative to the baseline vaccination path depicted in Figure $10 .{ }^{15}$

\subsection{The Toll of Vaccine Hesitancy}

Our counterfactual exercises compare the predicted number of COVID-19 related deaths in the baseline model with the same measure when we increase the levels of vaccine hesitancy to a country in the median of the distribution of hesitancy levels, and to a country at the top of the distribution. Our baseline roughly reflects the average hesitancy observed in the United Kingdom, the median of the distribution is represented by the hesitancy levels observed in the Republic of Korea, and the maximum hesitancy level we consider is that of France. In all cases, we average the data across the entire sample period to arrive at the level of hesitancy in each country.

\footnotetext{
14 There have been several reports of this across Europe and the U.S. In European countries, low willingness to take the AstraZeneca vaccine has left millions of doses unused by the end of February - that is, before the temporary prohibition of the vaccine due to potential side effects, including blood clots (see https://www.ft.com/content/767fdd85-5329-479d-b565-4ec85d28b492). In the U.S., some healthcare providers have struggled to administer doses due to lack of demand, especially in underserved communities (for one example, see https://www.nbcbayarea.com/investigations/nearly-100k-vaccine-doses-unused-in-santa-claracounty-smaller-providers-struggling/2454267/).

15 The path depicted in Figure 10 is the projected vaccination path for the United Kingdom produced by Radzikowski and Dizioli (2021) based on data obtained from Airfinity, a predictive science company. Note that this does not necessarily reflect the realized number of daily vaccinations in the country going forward, and is used only as a common baseline to compare the effects of different levels of vaccine hesitancy.
} 
We analyze two different scenarios, described below, that differ based on authorities' ability to keep the pace of vaccination rollouts. The vaccine hesitancy levels are described in Table 2.

\section{Figure 10: Baseline Vaccination Path}

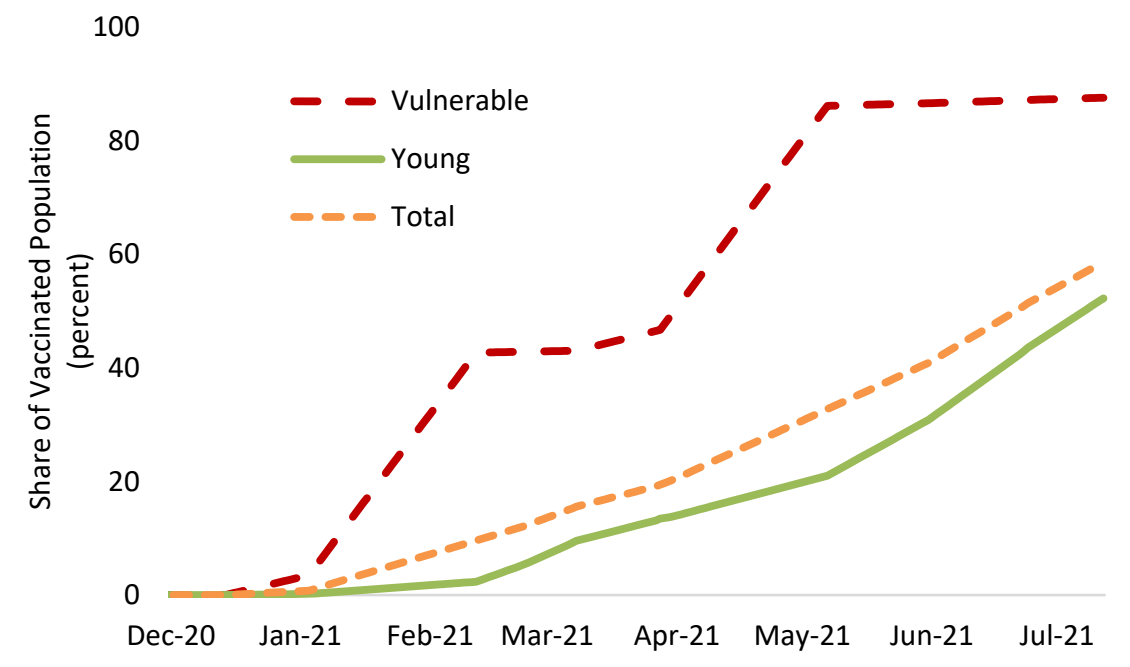

Source: Projected vaccination path from Radzikowski and Dizioli (2021) based on UK data.

Table 2: Vaccine Hesitancy Thresholds

\begin{tabular}{l|ll|ll|ll}
\multicolumn{2}{c}{ Baseline } & \multicolumn{2}{c}{ Median } & \multicolumn{2}{c}{ Max } \\
\hline $\begin{array}{l}\text { Share of the population that } \\
\text { wants to be vaccinated }\end{array}$ & Vulnerable & Young & Vulnerable & Young & Vulnerable & Young \\
& $89.35 \%$ & $74.07 \%$ & $75.00 \%$ & $62.07 \%$ & $57.48 \%$ & $34.71 \%$ \\
\hline
\end{tabular}

Scenario 1. In the first scenario, we assume that both effects discussed above play a role in the vaccination effort. The vaccine hesitancy cap is introduced by changing the number of daily vaccinations for a group to zero once the cumulative share of the vaccinated population in that group reaches the threshold in Table $2 .{ }^{16}$ In addition, the pace of the vaccine rollout is also affected by, and in proportion to, the level of hesitancy in the country. For example, suppose that the baseline has $v_{t}^{v}$ vaccines administered each day to the vulnerable, $v_{t}^{y}$ vaccines administered to the young, and we change vaccine hesitancy to its maximum level in Table 2 . The

\footnotetext{
16 This does not affect the vaccination path for other groups (i.e., we do not allow for the reallocation of vaccines to another group that hasn't reached its cap yet). The cap is only binding in scenario 2; in scenario 1, due to the slower vaccination pace, the thresholds are not reached in the time frame we consider.
} 
counterfactual number of vaccines administered per day would be $v_{t}^{v} \times \frac{57.48}{89.35}$ for the vulnerable population and $v_{t}^{y} \times \frac{34.71}{74.07}$ for the young.

Figure 11: Deaths related to COVID-19 in scenario 1
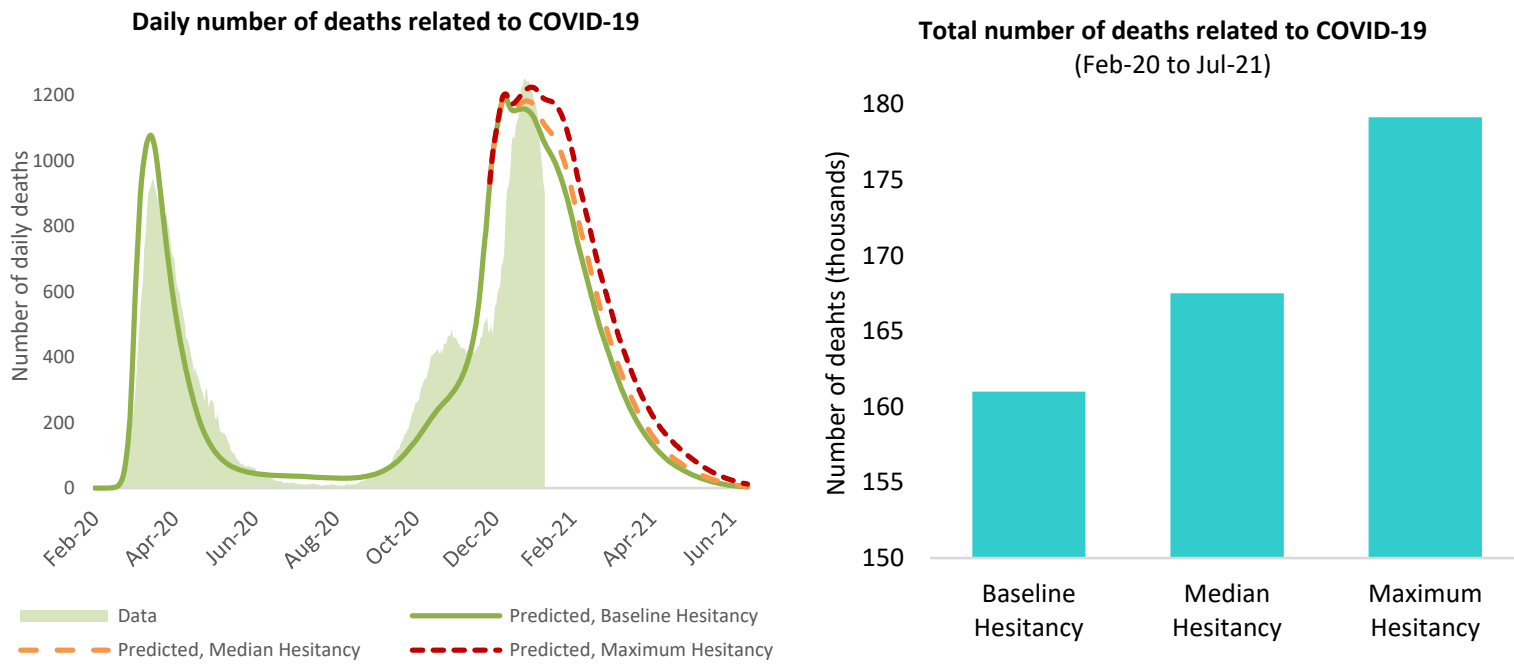

Figure 11 (left panel) shows the number of daily deaths related to COVID-19 in the United Kingdom (baseline), both in the data and predicted by the model. Note that the model does a fairly good job at matching the data picking up both waves of the disease in the UK (in large part, this reflects the mobility and contact data; see Figure B.2). Starting in end-December 2020, when the vaccine rollout began, we also include the predicted number of daily deaths under different levels of vaccine hesitancy.

In the right panel of the figure, we aggregate the predicted number of deaths between February 2020 and mid-July 2021. From these numbers, it is clear that vaccine hesitancy could have devastating effects for the country. Increasing the level of vaccine hesitancy from the baseline to the maximum level would cost roughly 18,000 lives, which is 11 percent more than the total death toll that is expected in the current baseline. We see a similar picture when looking at the number of infected cases (see appendix C).

Scenario 2. In the second scenario, we maintain the hesitancy cap but assume that governments are able to maintain the same pace of vaccination, regardless of the level of vaccine hesitancy. The outcomes in this case, shown in Figure 12, are very different. The trajectory of all three curves (left panel) are the same until the beginning of April, when the 57.48 percent vaccination cap is reached for the vulnerable population. The second cap (75 percent) for the vulnerable is reached by the end of that same month, and the 34.71 percent cap for the young is reached in June.

The key difference in this case is that by the time the curves diverge, the number of cases is considerably lower (see appendix C) and a much larger share of the population is already 
immune. Vaccine hesitancy is still costly in terms of more cases and deaths, but as shown in the right panel of Figure 12, the number of excess deaths relative to the baseline is much lower. When comparing hesitancy levels between the baseline and the maximum hesitancy levels, there are slightly less than 1,000 excess deaths, which is almost 20 times lower than scenario 1.

Figure 12: Deaths related to COVID-19 in Scenario 2
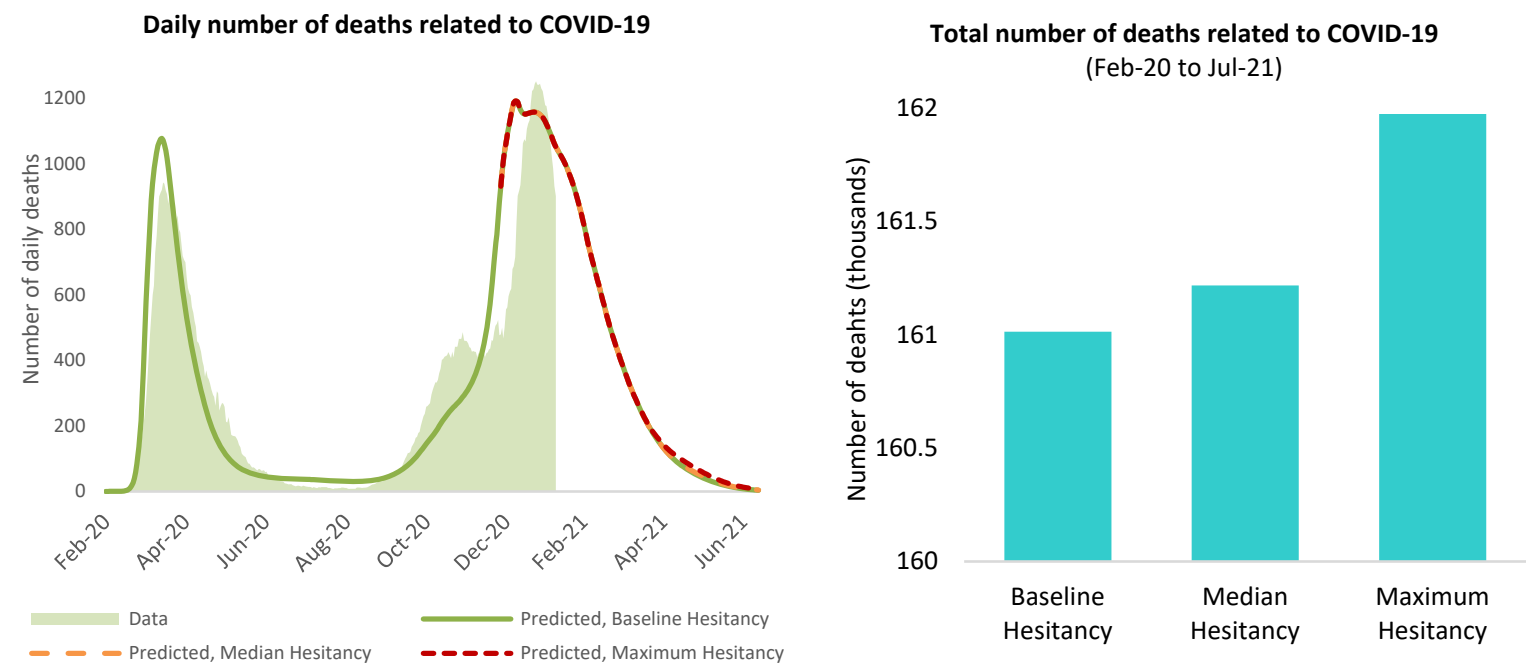

Discussion. There are two important factors that play a role in the predictions above. First, note that the impact of vaccine hesitancy on the number of deaths is non-linear. In scenario 2, this happens because the vaccination cap is reached earlier when vaccine hesitancy is higher, which means that fewer people are vaccinated by then, and the chances of infection are higher. In scenario 1 , this effect is compounded by a slower rollout, which causes the curves to diverge earlier and further increases the chances of viral infection at any point in time.

Second, the number of new infections crucially depends on assumptions about mobility and the extent to which people adhere to safety protocols, and we adopt a conservative stance in both cases. The rate of infections remains at its lowest point $\left(\beta_{s}\right)$ once it is reached, which means that adherence to mask-wearing and other safety protocols is maintained even as most people get vaccinated. In addition, the number of daily contacts slowly increases, but never reaches its prepandemic levels in the time frame considered. It is also worth mentioning that a higher level of hesitancy leads to a higher peak in daily cases (in scenario 1). While not included in our model, this can lead to a higher rate of mortality due to overcrowded ICUs. A relaxation of any of those assumptions in the model could lead to more deaths due to vaccine hesitancy in both scenarios.

\subsection{Policy Implications}

The results presented in this section point to one clear policy implication: vaccine hesitancy can have a significant impact on pandemic dynamics if allowed to slow down the pace of vaccination. 
As a result, health authorities should focus on speeding up vaccine rollout until every willing adult has received their shot.

Achieving this goal might involve moving quickly through priority groups if demand for vaccines by the vulnerable population fails to meet supply. It could also entail having flexible days and times for appointments to receive a vaccine, multiple vaccination sites to avoid difficulties in commuting to a site, allowing individuals to choose their vaccine brand within the possibilities of each location (to avoid brand hesitancy), and allowing the population to pre-register or signal their intent to receive a vaccine so that authorities can assess demand with some presence. Because hesitancy and impediments to vaccinations can vary between regions/locations, it could also be advantageous to allow different vaccination sites to tailor the mix of policies to better meet their needs.

Another conclusion from the model presented above is that the path for mobility and other individual precautions taken to avoid infection (wearing masks and adhering to social distancing) could also play a key role in determining the toll of the pandemic. In our simulations, we assume that people remain vigilant, so that transmission is never as easy as it was at the beginning of the pandemic. Relaxing those measures could increase the number of deaths even if authorities are able to keep the pace of vaccination. It is also worth noticing that when the rate of infection is low, the level of vaccination required to achieve herd immunity is lower.

Finally, decreasing vaccine hesitancy also has myriad other benefits that are not directly related to the number of COVID-19 related deaths. A faster vaccine rollout will allow communities to quickly reach herd immunity and safely reopen the economy, allowing for the recovery of economic activity and growth. In addition, having a larger share of the population vaccinated can decrease the chances that new variants of the virus evolve.

\section{Conclusion}

While there has been steady progress towards resolving global vaccine supply constraints in recent months, vaccine hesitancy still poses serious challenges to achieving herd immunity. In this paper, we use individual-level survey data for 17 countries between November 2020 and April 2021 to understand the drivers and implications of COVID-19 vaccine demand, and what aspects should be prioritized when designing policies to tackle hesitancy.

Across our entire sample, nearly 40 percent of respondents are either unsure or unwilling to take the vaccine. There are also considerable differences in vaccine hesitancy across and within countries, which are correlated with pre-pandemic measures of general vaccine hesitancy. However, a positive development is that COVID-19 vaccine demand has been rising since the first effective vaccine was announced in November 2020, suggesting that hesitancy can be mitigated to some extent. 
Turning to individual-level data, we find that there are systematic differences in vaccine demand across demographic groups, with higher demand among older cohorts, and also among men-a gender gap that is consistent across ages and robust to controlling for household composition. Consistent with the pre-pandemic literature on vaccine hesitancy, these demographic differences are, in turn, partly attributable to differences in attitudes and beliefs. Important drivers of vaccine demand include individual concerns about the (potential) severity of COVID-19, self-reported compliance with protective behaviors, and overall trust in government.

Finally, we also show that vaccine demand is linked to how information is shared with peers, such as friends and family. People who are more exposed to warnings against the vaccine from peers are also less likely to want to take the shot, and, conversely, hesitant respondents are also more likely to share negative information about COVID-19 vaccines with their peers. This correlation suggests that managing information about COVID-19 vaccines, including through public health policies and communication targeted at informing the public about vaccine safety and effectiveness, are key to containing vaccine hesitancy.

Building on these empirical results, in the second part of the paper we extend a canonical SIR model to examine the implications of vaccine hesitancy for pandemic dynamics. We consider two channels through which hesitancy can affect vaccine rollouts, namely a reduction in the overall share of the population that gets vaccinated and a slowing down of mass vaccination programs. When both effects are operational, hesitancy can have a dramatic impact on COVID-19 dynamics. This suggests that the policy benefits of tackling vaccine hesitancy and increasing vaccination speed could be very large.

Our paper points towards several interesting avenues for future research. First, our results show that vaccine hesitancy can cluster geographically and across specific social networks, partly due to peer effects. This suggests ways to target policies to promote vaccine demand, but also the need to monitor potential local flare-ups of COVID-19 cases even after herd immunity is achieved at the country level. Second, it would be useful to understand if mandatory vaccination strategies are optimal and how they could be implemented effectively (e.g., linked to employment, school), given that COVID-19 vaccine hesitancy is also strongly correlated with broader distrust of institutions and noncompliance with social distancing recommendations. Third, further research on higher hesitancy among working-age women, and also households with children is important given that many of these individuals will be closely involved in COVID19 vaccination decisions for their children once those vaccines become available. Finally, it would be interesting to embed our modelling results in a broader economic model, to understand the potential economic impact of vaccine hesitancy, both over the short and medium-term. 


\section{References}

Acemoglu, D., Makhdoumi, A., Malekian, A. and Ozdaglar, A., (2020). Testing, voluntary social distancing and the spread of an infection, (Working Paper No. 27483). National Bureau of Economic Research. http://www.nber.org/papers/w27483

Allcott, H., Boxell, L., Conway, J. C., Gentzkow, M., Thaler, M., and Yang, D. Y., (2020). Polarization and public health: partisan differences in social distancing during the coronavirus pandemic, (Working Paper No. 26946). National Bureau of Economic Research. https://doi.org/10.3386/w26946

Alsan, M., and Wanamaker, M., (2018). Tuskegee and the health of black men. The Quarterly Journal of Economics, Vol. 133, Issue 1, 407-455.

Alsan, M., and Eichmeyer, S., (2021). Persuasion in medicine: messaging to increase vaccine demand, (Working Paper No. 28593). National Bureau of Economic Research. https://www.nber.org/papers/w28593

Barrios, J. M., Benmelech, E., Hochberg, Y. V., Sapienza, P. and Zingales, L., (2021). Civic capital and social distancing during the Covid-19 pandemic. Journal of Public Economics, 193. 104310. 10.1016/j.jpubeco.2020.104310.

Barrios, J. M., and Hochberg, Y., (2020). Risk perception through the lens of politics in the time of the covid-19 pandemic, (Working Paper No. 27008). National Bureau of Economic Research. https://doi.org/10.3386/w27008

Bodine-Baron, E., Nowak, S., Varadavas, R. and Sood, N., (2013). Conforming and non-conforming peer effects in vaccination decisions (Working Paper No. 19528). National Bureau of Economic Research. https://www.nber.org/papers/w19528

Brewer, N. T., Chapman, G., Rothman, A., Leask, A., and Kempe, A., (2017). Increasing vaccination: putting psychological science into action. Psychological Science in the Public Interest, 18, 149-207.

Bughin, J., Cincera, M., Peters, K., Reykowska, D., Zyszkiewicz, M. and Ohmed, R., (2021). Make it or break it: vaccination intent at the time of Covid-19. Centre for Economic Policy Research, Covid Economics 65, 20 January 2021: 188-222.

Carrieri, V., Madio, L., Principe, F., (2019). Vaccine hesitancy and (fake) news: quasi-experimental evidence from Italy. Health Economics, 2019; 28: 1377- 1382. https://doi.org/10.1002/hec.3937

Chen, F. and Toxvaerd, F. (2014). The economics of vaccination. Journal of Theoretical Biology, 363, 105-117.

Croson, R., and Gneezy, U., (2009). Gender differences in preferences. Journal of Economic Literature, 47 (2): 448-74. DOI: 10.1257/jel.47.2.448

Dabla-Norris, E., Khan, H. and Lima, F., (2021). What determines social distancing? Evidence from advanced and emerging market economies. IMF Working Paper, forthcoming 
Das, J., and Das, S., (2003). Trust, leaning and vaccination: A case study of a North Indian village. Social Science \& Medicine, 57(1):97-112. doi: 10.1016/s0277-9536(02)00302-7. PMID: 12753819.

Du, F., Chantler, T., Francis, M. R., Sun, F. Y., Zhang, X., Han, K., Rodewald, L., Yu, H., Tu, S., Larson, H. and Hou, Z., (2020). The determinants of vaccine hesitancy in China: a cross-sectional study following the Changchun Changsheng vaccine incident. Vaccine, 2020 Nov 3;38(47):7464-7471. doi: 10.1016/j.vaccine.2020.09.075. Epub 2020 Oct 9. PMID: 33041097.

Dupas, P. and Miguel, E., (2017). Chapter 1 - Impacts and determinants of health levels in low-income countries. Handbook of Economic Field Experiments, Editors: Abhijit V. Banerjee, Esther Duflo, North-Holland, Vol. 2, 3-93.

Eichenbaum, M., Rebelo, S. and Trabandt, M., (2021). The macroeconomics of epidemics. Working Paper.

Fan, Y., Orhun, A. Y., and Turjeman, D., (2020). Heterogeneous actions, beliefs, constraints and risk tolerance during the COVID-19 pandemic (Working Paper No. 27211). National Bureau of Economic Research. doi: 10.3386/w27211

Figueiredo, A., Simas, C., Karafillakis, E., Paterson, P. and Larson, H. J., (2020). Mapping global trends in vaccine confidence and investigating barriers to vaccine uptake: a large-scale retrospective temporal modelling study. The Lancet, Volume 396, Issue 10255, Pages 898-908, https://doi.org/10.1016/S0140-6736(20)31558-0

Galasso, V., Pons, V., Profeta, P., Becher, M., Brouard, S. and Foucault, M., (2020). Gender differences in COVID-19 attitudes and behavior: panel evidence from eight countries. Proceedings of the National Academy of Sciences of the United States of America, 202012520; DOI: 10.1073/pnas.2012520117

Lazarus, J.V., Ratzan, S.C., Palayew, A. et al., (2021). A global survey of potential acceptance of a COVID-19 vaccine. Nature Medicine 27, 225-228. https://doi.org/10.1038/s41591-020-1124-9.

Levin, A.T., Hanage, W.P., Owusu-Boaitey, N., et al. (2020). Assessing the age specificity of infection fatality rates for COVID-19: systematic review, meta-analysis, and public policy implications. European Journal of Epidemiology, volume 35, 1123-1138. https://doi.org/10.1007/s10654-02000698-1

Levine-Tiefenbrun, M., Yelin, P., Katz, R., Herzel, E., Golan, Z., Schreiber, L., Wolf, T., Nadler, V., Ben-Tov, A., Kuint, J., Gazit, S., Patalon, T., Chodick, G., and Kishony, R. (2021). Decreased SARS-CoV-2 viral load following vaccination. medRxiv, pre-print. https://doi.org/10.1101/2021.02.06.21251283

Loomba, S., Figueiredo, A., Piatek, S.J. et al., (2021). Measuring the impact of COVID-19 vaccine misinformation on vaccination intent in the UK and USA. Nature Human Behaviour 5, 337-348. https://doi.org/10.1038/s41562-021-01056-1

Martinez-Bravo, M., and Stegmann, A., (2021). In vaccines we trust? the effects of the CIA's vaccine ruse on immunization in Pakistan. Center for Economic and Policy Research, Discussion Paper No. DP15847, Available at SSRN: https://ssrn.com/abstract=3795231 
Milkman, K., Beshears, J., Choi, J., Laibson, D., and Madrian, B., (2011). Using implementation intentions prompts to enhance influenza vaccination rates. Proceedings of the National Academy of Sciences of the United States of America, 108, 10415-10420.

Murphy, J., Vallières, F., Bentall, R.P. et al., (2021). Psychological characteristics associated with COVID19 vaccine hesitancy and resistance in Ireland and the United Kingdom. Nature Communications, volume 12, 29. https://doi.org/10.1038/s41467-020-20226-9

Neumann-Böhme, S., Varghese, N. E., Sabat, I., Barros, P. P., Brouwer, W., Van-Exel, J., Schreyögg, J. and Stargardt, T., (2020). Once we have it, will we use it? A European survey on willingness to be vaccinated against COVID-19. The European Journal of Health Economics, 2020 Sep;21(7):977-982. doi: 10.1007/s10198-020-01208-6.

O'Driscoll, M., Ribeiro Dos Santos, G., Wang, L. et al., (2021). Age-specific mortality and immunity patterns of SARS-CoV-2. Nature, 590, 140-145. https://doi.org/10.1038/s41586-020-2918-0

Omer, S. B., Salmon, D. A., Orenstein, W. A., DeHart, M. P. and Halsey, N., (2009). Vaccine refusal, mandatory immunization, and the risks of vaccine-preventable diseases. New England Journal of Medicine; 360:1981-1988 DOI: 10.1056/NEJMsa0806477

Oster, E., (2018). Does disease cause vaccination? disease outbreaks and vaccination response. Journal of Health Economics, Volume 57, Pages 90-101

Papageorge, N. W., Zahn, M. V., Belot, M., Broek-Altenburg E. V. D., Choi, S., Jamison, J. C., and Tripodi, E., (2020). Socio-demographic factors associated with self-protecting behavior during the Covid19 pandemic, (Working Paper No. 27378). National Bureau of Economic Research. doi $10.3386 / \mathrm{w} 27378$

Paul, E., Steptoe, A. and Fancourt, D., (2021). Attitudes towards vaccines and intention to vaccinate against COVID-19: Implications for public health communications. The Lancet Regional Health Europe, Volume 1, 2021, 100012, ISSN 2666-7762, https://doi.org/10.1016/j.lanepe.2020.100012.

Radzikowski, A. and Dizioli, A., (2021). IMF Research Department's Pandemic Tool. International Monetary Fund, forthcoming.

Rao, N., Mobius, M. M. and Rosenblat, T., (2007). Social networks and vaccination decisions. Federal Reserve Bank of Boston Research, Working Paper No. 07-12, Available at SSRN: http://dx.doi.org/10.2139/ssrn.1073143

Rowthorn, R. and Toxvaerd, F., (2020). On the management of population immunity. Bennett Institute, Working Paper.

Sadaf, A., Richards, J. L., Glanz, J., Salmon. D. A. and Omer, S. B., (2013). A systematic review of interventions for reducing parental vaccine refusal and vaccine hesitancy. Vaccine. 13:31(40):4293304. doi: 10.1016/j.vaccine.2013.07.013. Epub 2013 Jul 13. PMID: 23859839. 
Sato, R. and Takasaki, Y., (2019). Peer effects on vaccination behavior: experimental evidence from rural Nigeria. Economic Development and Cultural Change 68, 93-129 (2019).

Simonov, A., Sacher, S., Dubé, J. P and Biswas, S., (2020). The persuasive effect of Fox News: noncompliance with social distancing during the COVID-19 pandemic. Social Science Research Network Electronic Journal DOI: 10.2139/ssrn.3604214

Thunström, L., Ashworth, M., Finnoff, D. and Newbold, S. C., (2020). Hesitancy towards a COVID-19 vaccine and prospects for herd immunity. Centre for Economic Policy Research, Covid Economics 35,7 July $2020: 1-50$. 


\section{A Tables}

Table A. 1 Agree to be Vaccinated vs Disagree to be Vaccinated - Baseline Model

\begin{tabular}{|c|c|c|c|c|}
\hline & (1) & (2) & (3) & (4) \\
\hline Number Children & $\begin{array}{l}-0.013^{* *} \\
(0.004)\end{array}$ & $\begin{array}{c}-0.015^{\star \star \star} \\
(0.004)\end{array}$ & $\begin{array}{c}-0.006^{\star *} \\
(0.003)\end{array}$ & $\begin{array}{l}-0.006^{*} \\
(0.003)\end{array}$ \\
\hline Easy Access to Vaccine & $\begin{array}{c}0.115^{\star \star \star} \\
(0.017)\end{array}$ & $\begin{array}{c}0.113^{* * *} \\
(0.016)\end{array}$ & $\begin{array}{c}0.044^{\star * *} \\
(0.010)\end{array}$ & $\begin{array}{c}0.045^{* * *} \\
(0.012)\end{array}$ \\
\hline Safe Behavior & & $\begin{array}{c}0.528^{\star \star \star} \\
(0.083)\end{array}$ & $\begin{array}{c}0.162^{\star \star \star} \\
(0.034)\end{array}$ & $\begin{array}{c}0.169^{\star \star \star} \\
(0.033)\end{array}$ \\
\hline Wears Masks & & $\begin{array}{c}0.098^{\star \star *} \\
(0.026)\end{array}$ & $\begin{array}{l}0.045^{\star \star} \\
(0.016)\end{array}$ & $\begin{array}{c}0.047^{\star \star \star} \\
(0.015)\end{array}$ \\
\hline \multicolumn{5}{|c|}{ Worried About COVID-19 } \\
\hline 2 & & & $\begin{array}{c}0.044^{\star \star \star} \\
(0.006)\end{array}$ & $\begin{array}{c}0.031^{\star \star *} \\
(0.005)\end{array}$ \\
\hline 3 & & & $\begin{array}{c}0.090^{\star \star \star} \\
(0.010)\end{array}$ & $\begin{array}{c}0.084^{\star \star *} \\
(0.008)\end{array}$ \\
\hline 4 & & & $\begin{array}{c}0.159^{\star \star \star} \\
(0.013)\end{array}$ & $\begin{array}{c}0.151^{\star \star *} \\
(0.011)\end{array}$ \\
\hline 5 (Str. Agree) & & & $\begin{array}{c}0.225^{\star \star \star} \\
(0.015)\end{array}$ & $\begin{array}{c}0.221^{\star \star *} \\
(0.010)\end{array}$ \\
\hline \multicolumn{5}{|c|}{ Worried About Side Effects } \\
\hline 2 & & & $\begin{array}{c}0.030^{\star \star *} \\
(0.007)\end{array}$ & $\begin{array}{l}0.023^{\star *} \\
(0.008)\end{array}$ \\
\hline 3 & & & $\begin{array}{l}-0.003 \\
(0.012)\end{array}$ & $\begin{array}{l}-0.007 \\
(0.013)\end{array}$ \\
\hline 4 & & & $\begin{array}{c}-0.098^{\text {*** }} \\
(0.015)\end{array}$ & $\begin{array}{c}-0.109^{\star * *} \\
(0.014)\end{array}$ \\
\hline 5 (Str. Agree) & & & $\begin{array}{c}-0.284^{* * *} \\
(0.018)\end{array}$ & $\begin{array}{c}-0.297^{\star \star *} \\
(0.018)\end{array}$ \\
\hline \multicolumn{5}{|c|}{ Gov. Provide Effective Vaccine } \\
\hline 2 & & & $\begin{array}{c}0.045^{\star \star *} \\
(0.009)\end{array}$ & $\begin{array}{c}0.035^{\star \star \star} \\
(0.011)\end{array}$ \\
\hline 3 & & & $\begin{array}{c}0.137^{\star * \star} \\
(0.012)\end{array}$ & $\begin{array}{c}0.126^{\star \star \star} \\
(0.013)\end{array}$ \\
\hline 4 & & & $\begin{array}{c}0.393^{* * *} \\
(0.014)\end{array}$ & $\begin{array}{c}0.374^{\star \star *} \\
(0.017)\end{array}$ \\
\hline 5 (Str. Agree) & & & $\begin{array}{c}0.496^{* * *} \\
(0.017)\end{array}$ & $\begin{array}{c}0.476^{\star \star \star} \\
(0.020)\end{array}$ \\
\hline \multicolumn{5}{|c|}{ Confidence in HC System } \\
\hline 2 (Not Much) & & & & $\begin{array}{c}0.017^{\star \star \star} \\
(0.005)\end{array}$ \\
\hline 3 (Not Sure) & & & & $\begin{array}{l}-0.017^{*} \\
(0.009)\end{array}$ \\
\hline 4 (Fair) & & & & $\begin{array}{c}0.044^{\star \star *} \\
(0.009)\end{array}$ \\
\hline 5 (A Lot) & & & & $\begin{array}{c}0.048^{\star \star *} \\
(0.012)\end{array}$ \\
\hline \multicolumn{5}{|c|}{ Gov Handled Pandemic Well } \\
\hline 2 & & & & $\begin{array}{l}-0.009 \\
(0.009)\end{array}$ \\
\hline 3 & & & & $\begin{array}{c}-0.074^{\star \star *} \\
(0.012)\end{array}$ \\
\hline 4 & & & & $\begin{array}{l}-0.024^{*} \\
(0.011)\end{array}$ \\
\hline 5 (Str. Agree) & & & & $\begin{array}{l}-0.020 \\
(0.015) \\
\end{array}$ \\
\hline Observations & 83805 & 83805 & 83805 & 60521 \\
\hline Within R2 & 0.0300 & 0.0452 & 0.3141 & 0.3201 \\
\hline
\end{tabular}

All Specifications control for age group by gender, pre-existing health conditions, whether individuals had COVID-19 symptoms, and household size. We also include occupation and location-by-week fixed effects. Standard errors are clustered at the country level and shown in parenthesis. ${ }^{*}{ }^{* *}$ and ${ }^{* * *}$ indicate that coefficients are statistically different from 0 at the $10 \%$, $5 \%$, and $1 \%$ levels, respectively.

\section{CInternational Monetary Fund. Not for Redistribution}


Table A.2 Agree to be Vaccinated vs Disagree to be Vaccinated - Peer Effects

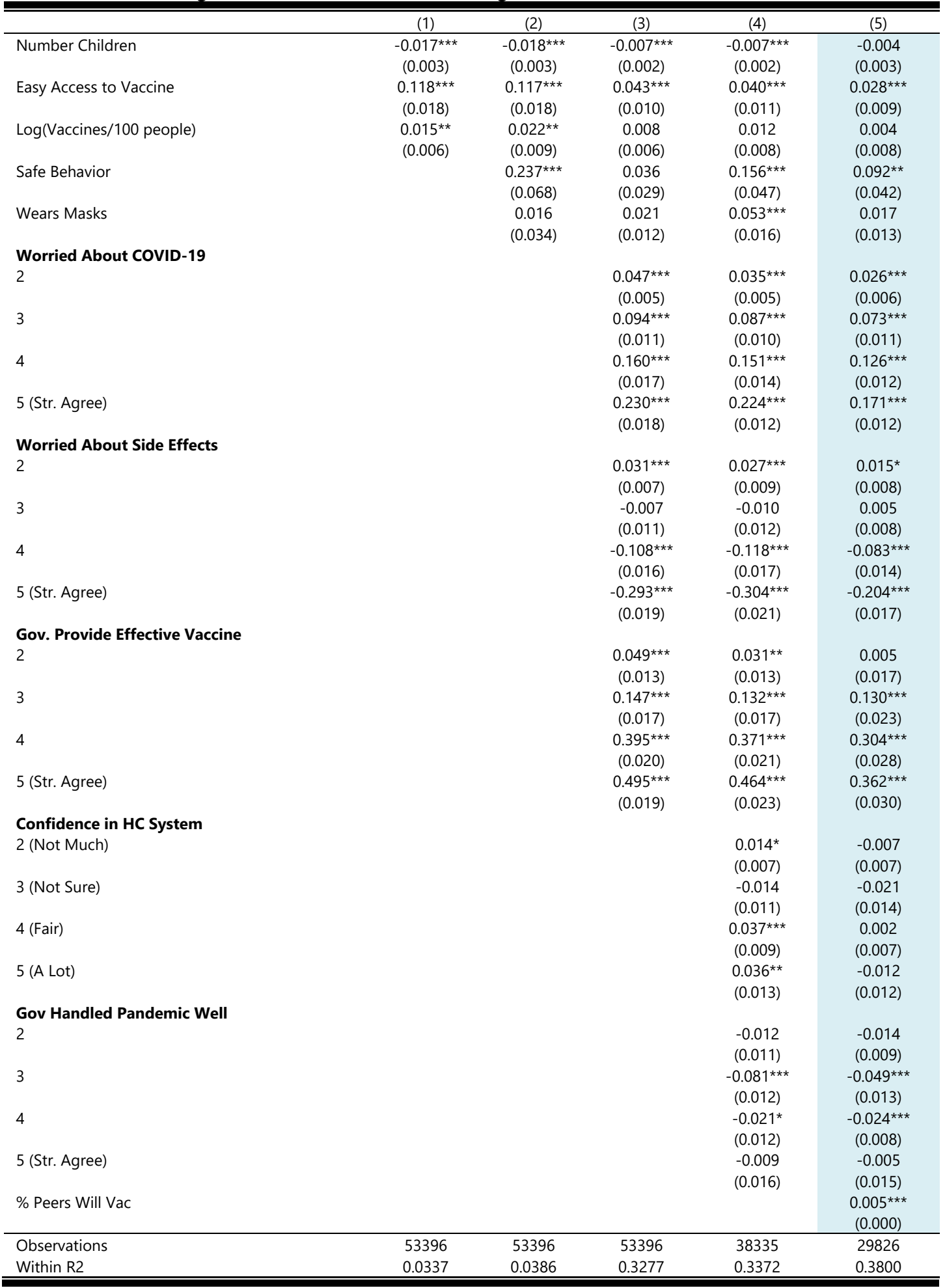

All Specifications control for age group by gender, pre-existing health conditions, whether individuals had COVID-19 symptoms, and household size. We also include occupation, week, and location fixed effects. Standard errors are clustered at the country level and shown in parenthesis. ${ }^{*}{ }^{* *}$ and ${ }^{* * *}$ indicate that coefficients are statistically different from 0 at the $10 \%$, $5 \%$, and $1 \%$ levels, respectively.

\section{CInternational Monetary Fund. Not for Redistribution}


Table A.3 Agree to be Vaccinated vs Unsure About Vaccination

\begin{tabular}{|c|c|c|c|c|}
\hline & (1) & (2) & (3) & (4) \\
\hline Number Children & $\begin{array}{l}-0.007^{\star} \\
(0.004)\end{array}$ & $\begin{array}{l}-0.009 * \star \\
(0.004)\end{array}$ & $\begin{array}{l}-0.006^{*} \\
(0.003)\end{array}$ & $\begin{array}{l}-0.007^{\star \star} \\
(0.003)\end{array}$ \\
\hline Easy Access to Vaccine & $\begin{array}{c}0.069^{\star \star \star} \\
(0.011)\end{array}$ & $\begin{array}{c}0.068^{\star \star \star} \\
(0.011)\end{array}$ & $\begin{array}{c}0.027^{\star \star *} \\
(0.008)\end{array}$ & $\begin{array}{l}0.022^{\star *} \\
(0.008)\end{array}$ \\
\hline Safe Behavior & & $\begin{array}{c}0.342^{\star * *} \\
(0.059)\end{array}$ & $\begin{array}{l}0.206^{\star * *} \\
(0.039)\end{array}$ & $\begin{array}{c}0.217^{\star \star \star} \\
(0.037)\end{array}$ \\
\hline Wears Masks & & $\begin{array}{c}0.074^{* * *} \\
(0.019)\end{array}$ & $\begin{array}{c}0.055^{\star \star *} \\
(0.013)\end{array}$ & $\begin{array}{c}0.056^{* \star *} \\
(0.014)\end{array}$ \\
\hline \multicolumn{5}{|c|}{ Worried About COVID-19 } \\
\hline 2 & & & $\begin{array}{l}-0.007 \\
(0.008)\end{array}$ & $\begin{array}{c}-0.019^{* *} \\
(0.008)\end{array}$ \\
\hline 3 & & & $\begin{array}{c}-0.033^{\star \star \star} \\
(0.009)\end{array}$ & $\begin{array}{c}-0.040^{\star * *} \\
(0.010)\end{array}$ \\
\hline 4 & & & $\begin{array}{c}0.054^{\star \star \star} \\
(0.006)\end{array}$ & $\begin{array}{c}0.046^{\star * *} \\
(0.006)\end{array}$ \\
\hline 5 (Str. Agree) & & & $\begin{array}{c}0.101^{\star \star *} \\
(0.007)\end{array}$ & $\begin{array}{c}0.094^{\star * \star} \\
(0.007)\end{array}$ \\
\hline \multicolumn{5}{|c|}{ Worried About Side Effects } \\
\hline 2 & & & $\begin{array}{l}0.008^{*} \\
(0.004)\end{array}$ & $\begin{array}{l}0.009^{*} \\
(0.005)\end{array}$ \\
\hline 3 & & & $\begin{array}{c}-0.063^{* * *} \\
(0.010)\end{array}$ & $\begin{array}{c}-0.061^{\star \star *} \\
(0.010)\end{array}$ \\
\hline 4 & & & $\begin{array}{c}-0.066^{\star * *} \\
(0.011)\end{array}$ & $\begin{array}{c}-0.068^{\star * *} \\
(0.011)\end{array}$ \\
\hline 5 (Str. Agree) & & & $\begin{array}{c}-0.168^{\star \star *} \\
(0.014)\end{array}$ & $\begin{array}{c}-0.171^{\star \star *} \\
(0.012)\end{array}$ \\
\hline \multicolumn{5}{|c|}{ Gov. Provide Effective Vaccine } \\
\hline 2 & & & $\begin{array}{c}-0.056^{* * *} \\
(0.010)\end{array}$ & $\begin{array}{c}-0.055^{\star * *} \\
(0.010)\end{array}$ \\
\hline 3 & & & $\begin{array}{c}-0.143^{* * *} \\
(0.025)\end{array}$ & $\begin{array}{c}-0.137^{* * *} \\
(0.021)\end{array}$ \\
\hline 4 & & & $\begin{array}{c}0.107^{\star \star \star} \\
(0.016)\end{array}$ & $\begin{array}{c}0.101^{\star \star \star} \\
(0.013)\end{array}$ \\
\hline 5 (Str. Agree) & & & $\begin{array}{c}0.163^{* \star *} \\
(0.016)\end{array}$ & $\begin{array}{c}0.153^{\star \star *} \\
(0.014)\end{array}$ \\
\hline \multicolumn{5}{|c|}{ Confidence in HC System } \\
\hline 2 (Not Much) & & & & $\begin{array}{l}0.023^{*} \\
(0.011)\end{array}$ \\
\hline 3 (Not Sure) & & & & $\begin{array}{l}-0.000 \\
(0.016)\end{array}$ \\
\hline 4 (Fair) & & & & $\begin{array}{c}0.058^{\star * \star} \\
(0.010)\end{array}$ \\
\hline 5 (A Lot) & & & & $\begin{array}{c}0.071^{* * *} \\
(0.012)\end{array}$ \\
\hline \multicolumn{5}{|c|}{ Gov Handled Pandemic Well } \\
\hline 2 & & & & $\begin{array}{l}-0.012^{*} \\
(0.006)\end{array}$ \\
\hline 3 & & & & $\begin{array}{c}-0.071^{\star \star *} \\
(0.012)\end{array}$ \\
\hline 4 & & & & $\begin{array}{c}-0.019^{\star *} \\
(0.007)\end{array}$ \\
\hline 5 (Str. Agree) & & & & $\begin{array}{c}-0.018^{\star} \\
(0.010) \\
\end{array}$ \\
\hline Observations & 71701 & 71701 & 71701 & 51615 \\
\hline Within R2 & 0.0191 & 0.0272 & 0.1772 & 0.1814 \\
\hline
\end{tabular}

All Specifications control for age group by gender, pre-existing health conditions, whether individuals had COVID-19 symptoms, and household size. We also include occupation and location-by-week fixed effects. Standard errors are clustered at the country level and shown in parenthesis. ${ }^{*}{ }^{* *}$ and ${ }^{* * *}$ indicate that coefficients are statistically different from 0 at the $10 \%$, $5 \%$, and $1 \%$ levels, respectively.

\section{CInternational Monetary Fund. Not for Redistribution}


Table A.4. Agree to be Vaccinated vs Disagree to be Vaccinated - Logit Specification (Odds Ratio)

\begin{tabular}{|c|c|c|c|c|}
\hline & (1) & (2) & (3) & (4) \\
\hline Number Children & $\begin{array}{c}0.946^{\star \star \star} \\
(0.018)\end{array}$ & $\begin{array}{c}0.938^{\star \star \star} \\
(0.018)\end{array}$ & $\begin{array}{l}0.963^{* *} \\
(0.016)\end{array}$ & $\begin{array}{l}0.958^{\star \star} \\
(0.017)\end{array}$ \\
\hline Easy Access to Vaccine & $\begin{array}{c}1.695^{\star \star \star} \\
(0.138)\end{array}$ & $\begin{array}{c}1.703^{\star \star \star} \\
(0.138)\end{array}$ & $\begin{array}{c}1.349 * * * \\
(0.093)\end{array}$ & $\begin{array}{c}1.349 * \star * \\
(0.100)\end{array}$ \\
\hline Safe Behavior & & $\begin{array}{c}3.090^{\star \star \star \star} \\
(0.876)\end{array}$ & $\begin{array}{c}1.551^{\star \star \star} \\
(0.250)\end{array}$ & $\begin{array}{c}3.090^{\star \star \star *} \\
(0.636)\end{array}$ \\
\hline Wears Masks & & $\begin{array}{c}1.017 \\
(0.140)\end{array}$ & $\begin{array}{c}1.040 \\
(0.094)\end{array}$ & $\begin{array}{c}1.353^{\star \star *} \\
(0.133)\end{array}$ \\
\hline \multicolumn{5}{|c|}{ Worried About COVID-19 } \\
\hline 2 & & & $\begin{array}{c}1.444^{* \star *} \\
(0.071)\end{array}$ & $\begin{array}{c}1.311^{\star * *} \\
(0.054)\end{array}$ \\
\hline 3 & & & $\begin{array}{c}1.964 * \star * \\
(0.153)\end{array}$ & $\begin{array}{c}1.844^{\star \star *} \\
(0.121)\end{array}$ \\
\hline 4 & & & $\begin{array}{c}3.093^{* * *} \\
(0.313)\end{array}$ & $\begin{array}{c}2.812^{\star * *} \\
(0.253)\end{array}$ \\
\hline 5 (Str. Agree) & & & $\begin{array}{c}5.001^{\star \star *} \\
(0.570)\end{array}$ & $\begin{array}{c}4.652^{\star \star \star} \\
(0.430)\end{array}$ \\
\hline \multicolumn{5}{|c|}{ Worried About Side Effects } \\
\hline 2 & & & $\begin{array}{l}1.129^{\star \star} \\
(0.060)\end{array}$ & $\begin{array}{c}1.051 \\
(0.065)\end{array}$ \\
\hline 3 & & & $\begin{array}{l}0.852^{*} \\
(0.080)\end{array}$ & $\begin{array}{l}0.818^{\star *} \\
(0.081)\end{array}$ \\
\hline 4 & & & $\begin{array}{c}0.480^{\star \star *} \\
(0.051)\end{array}$ & $\begin{array}{c}0.442^{\star * *} \\
(0.048)\end{array}$ \\
\hline 5 (Str. Agree) & & & $\begin{array}{c}0.162^{* \star *} \\
(0.022)\end{array}$ & $\begin{array}{c}0.146^{\star \star * *} \\
(0.020)\end{array}$ \\
\hline \multicolumn{5}{|c|}{ Gov. Provide Effective Vaccine } \\
\hline 2 & & & $\begin{array}{c}1.570^{\star \star \star} \\
(0.086)\end{array}$ & $\begin{array}{c}1.526^{\star \star *} \\
(0.080)\end{array}$ \\
\hline 3 & & & $\begin{array}{c}2.528^{\star \star \star} \\
(0.157)\end{array}$ & $\begin{array}{c}2.470 * \star \star \\
(0.139)\end{array}$ \\
\hline 4 & & & $\begin{array}{c}8.477^{\star \star \star} \\
(0.592)\end{array}$ & $\begin{array}{c}7.888^{\star \star *} \\
(0.594)\end{array}$ \\
\hline 5 (Str. Agree) & & & $\begin{array}{c}19.058^{\star \star \star} \\
(1.680)\end{array}$ & $\begin{array}{c}17.361^{* \star *} \\
(1.491)\end{array}$ \\
\hline \multicolumn{5}{|c|}{ Confidence in HC System } \\
\hline 2 (Not Much) & & & & $\begin{array}{c}1.159^{\star \star *} \\
(0.043)\end{array}$ \\
\hline 3 (Not Sure) & & & & $\begin{array}{c}0.949 \\
(0.061)\end{array}$ \\
\hline 4 (Fair) & & & & $\begin{array}{c}1.342^{\star \star *} \\
(0.071)\end{array}$ \\
\hline 5 (A Lot) & & & & $\begin{array}{c}1.420^{\star * *} \\
(0.111)\end{array}$ \\
\hline \multicolumn{5}{|c|}{ Gov Handled Pandemic Well } \\
\hline 2 & & & & $\begin{array}{c}0.984 \\
(0.059)\end{array}$ \\
\hline 3 & & & & $\begin{array}{c}0.663^{\star \star * *} \\
(0.054)\end{array}$ \\
\hline 4 & & & & $\begin{array}{c}0.906 \\
(0.067)\end{array}$ \\
\hline 5 (Str. Agree) & & & & $\begin{array}{c}0.901 \\
(0.092)\end{array}$ \\
\hline Observations & 83799 & 83799 & 83799 & 60519 \\
\hline Pseudo R2 & 0.0656 & 0.0693 & 0.3035 & 0.3098 \\
\hline
\end{tabular}

Note: table displays odds ratios.

All Specifications control for age group by gender, pre-existing health conditions, whether individuals had COVID-19 symptoms and household size. We also include occupation, week, and location. Standard errors are clustered at the country level and shown in parenthesis. * ${ }^{* *}$ and ${ }^{* * *}$ indicate that logit coefficients are statistically different from 0 at the $10 \%, 5 \%$, and $1 \%$ levels, respectively.

\section{CInternational Monetary Fund. Not for Redistribution}


Table A.5: Select survey questions

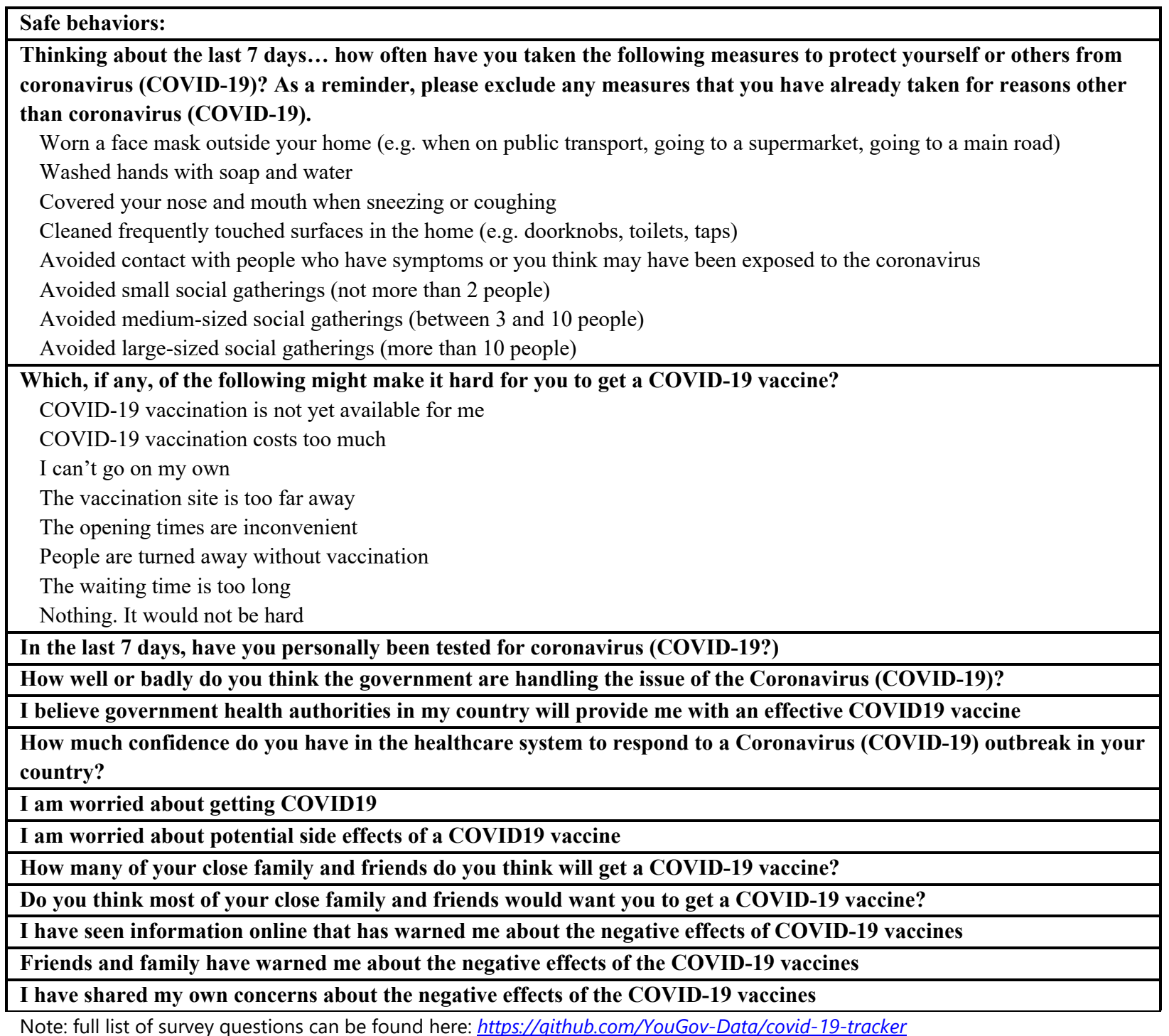

Note: full list of survey questions can be found here: https://github.com/YouGov-Data/covid-19-tracker 


\section{B. Figures}

Figure B.1: Data availability by Country and Week

\begin{tabular}{|c|c|c|c|c|c|c|c|c|c|c|c|c|c|c|c|c|c|c|c|}
\hline Week of (Friday) & $11 / 11$ & $11 / 18$ & $12 / 16$ & $12 / 23$ & $1 / 1$ & $1 / 8$ & $1 / 15$ & $1 / 22$ & $1 / 29$ & $2 / 5$ & $2 / 12$ & $2 / 19$ & $2 / 26$ & $3 / 5$ & $3 / 12$ & $3 / 19$ & $3 / 26$ & $4 / 2$ & Total \\
\hline AUS & 1 & & 1 & 1 & 1 & 1 & 1 & 1 & 1 & 1 & 1 & 1 & 1 & 1 & 1 & 1 & 1 & 1 & 17 \\
\hline CAN & 1 & 1 & 1 & 1 & 1 & 1 & 1 & 1 & 1 & 1 & 1 & 1 & 1 & 1 & 1 & 1 & 1 & 1 & 18 \\
\hline DEU & 1 & & 1 & & 1 & 1 & 1 & 1 & 1 & 1 & 1 & 1 & 1 & 1 & 1 & 1 & 1 & & 15 \\
\hline DNK & 1 & & 1 & & 1 & 1 & 1 & 1 & 1 & 1 & 1 & 1 & 1 & 1 & 1 & 1 & 1 & & 15 \\
\hline ESP & 1 & & 1 & & 1 & 1 & 1 & 1 & 1 & 1 & 1 & 1 & 1 & 1 & 1 & 1 & 1 & & 15 \\
\hline FIN & 1 & & 1 & & 1 & 1 & 1 & & & & & & & & & & & & 5 \\
\hline FRA & 1 & & 1 & & 1 & 1 & 1 & 1 & 1 & 1 & 1 & 1 & 1 & 1 & 1 & 1 & 1 & & 15 \\
\hline GBR & 1 & & 1 & 1 & 1 & 1 & 1 & 1 & 1 & 1 & 1 & 1 & 1 & 1 & 1 & 1 & 1 & & 16 \\
\hline ISR & & & & & & & & & 1 & 1 & 1 & 1 & 1 & 1 & 1 & 1 & 1 & & 9 \\
\hline ITA & 1 & & 1 & & 1 & 1 & 1 & 1 & 1 & 1 & 1 & 1 & 1 & 1 & 1 & 1 & 1 & & 15 \\
\hline JPN & 1 & & 1 & & 1 & 1 & 1 & 1 & 1 & 1 & & 1 & & & 1 & 1 & 1 & & 12 \\
\hline KOR & 1 & 1 & 1 & & 1 & 1 & 1 & 1 & 1 & 1 & 1 & 1 & 1 & 1 & 1 & 1 & 1 & & 16 \\
\hline NLD & 1 & & 1 & & 1 & 1 & 1 & 1 & 1 & 1 & & & & & & & & & 8 \\
\hline NOR & 1 & 1 & 1 & 1 & 1 & 1 & 1 & 1 & 1 & 1 & 1 & 1 & 1 & 1 & 1 & 1 & 1 & & 17 \\
\hline SGP & 1 & 1 & 1 & 1 & 1 & 1 & 1 & 1 & 1 & 1 & 1 & 1 & 1 & 1 & 1 & 1 & 1 & 1 & 18 \\
\hline SWE & 1 & & 1 & & 1 & 1 & 1 & 1 & 1 & 1 & 1 & 1 & 1 & 1 & 1 & 1 & 1 & & 15 \\
\hline USA & & & & & & & & & & & & 1 & 1 & 1 & 1 & 1 & 1 & 1 & 7 \\
\hline Total & 15 & 4 & 15 & 5 & 15 & 15 & 15 & 14 & 15 & 15 & 13 & 15 & 14 & 14 & 15 & 15 & 15 & 4 & \\
\hline
\end{tabular}

Note: This figure shows survey wave dates for each country.

Figure B.2: Mobility to Work and Number of Daily Contacts

Mobility Relative to Pre-pandemic Baseline

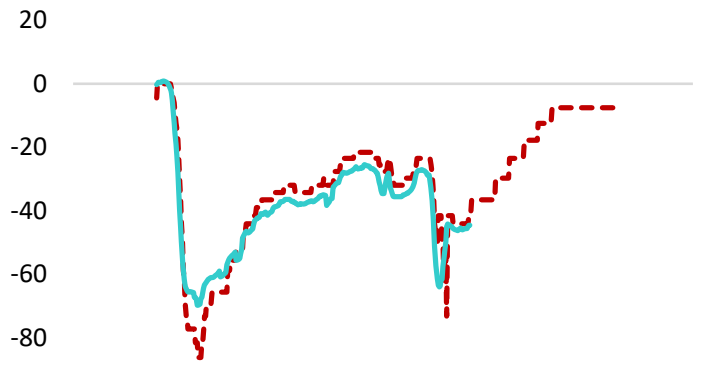

$-100$

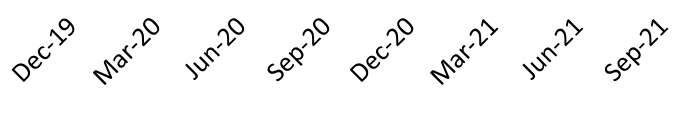

Mobility and Daily Contacts

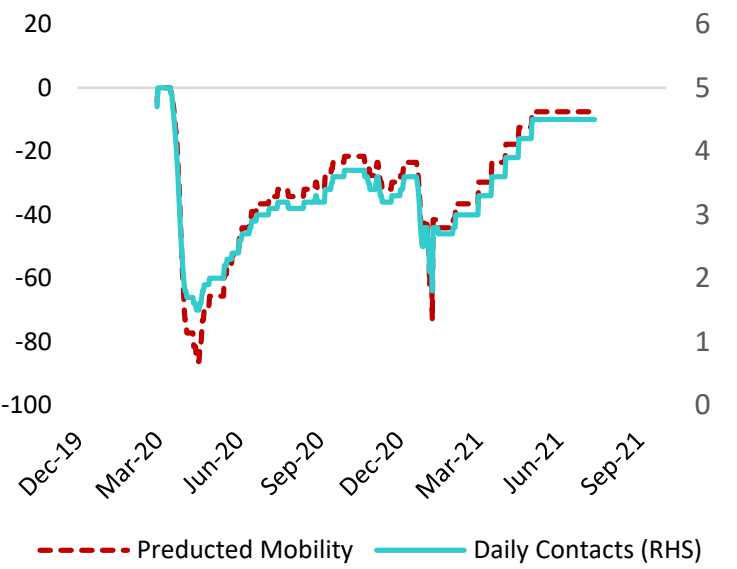




\section{Vaccine Hesitancy and the Pandemic Dynamics: COVID-19 Cases}

Here we present the number of COVID-19 cases under each scenario discussed in Section 4 of the main text. As seen in the figures below, the number of cases follows the same pattern as the number of deaths (although at a larger scale) and thus the same intuition applies.

Scenario 1. Vaccine hesitancy slows down the pace of vaccination and introduces a cap at the total number of people vaccinated at any point in time.
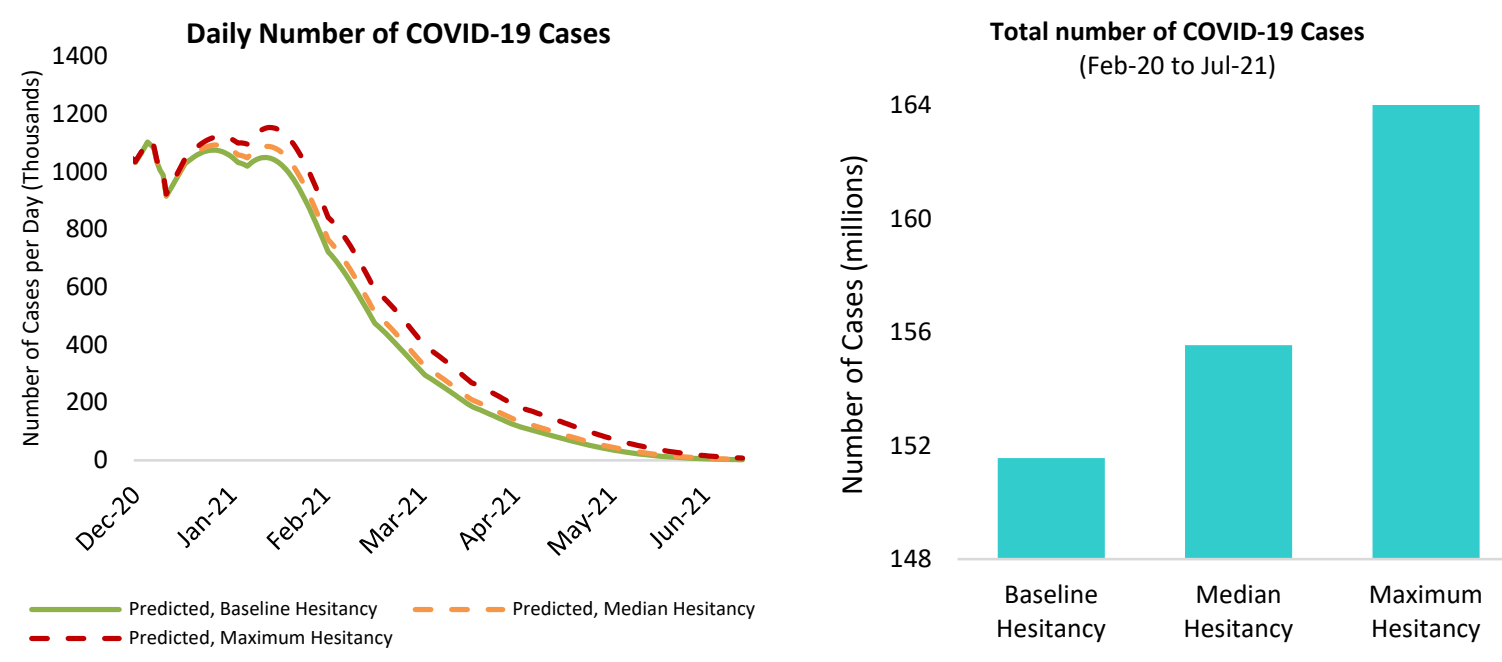

Scenario 2. Authorities adapt to hesitancy and keep the vaccination pace, but the cap remains.
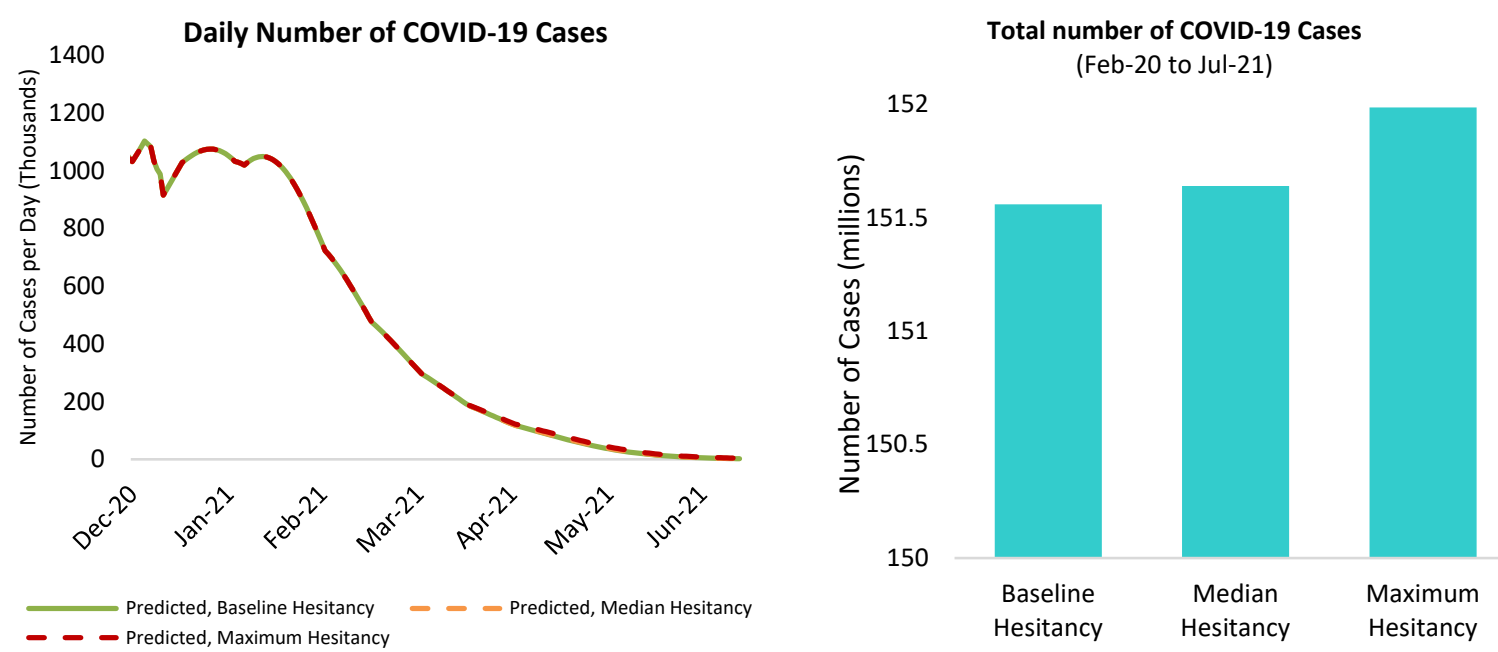